\title{
RIO BLANCO ELECTRONICS
}

O. H, Krause, I. B. Carson, M. F. Iaroska, S. I. Spataro, and G. E. Russell

\author{
April 8, 1974
}

Preparad for US. Alomic Energy Commission under contract No. W-7405 Eng 48

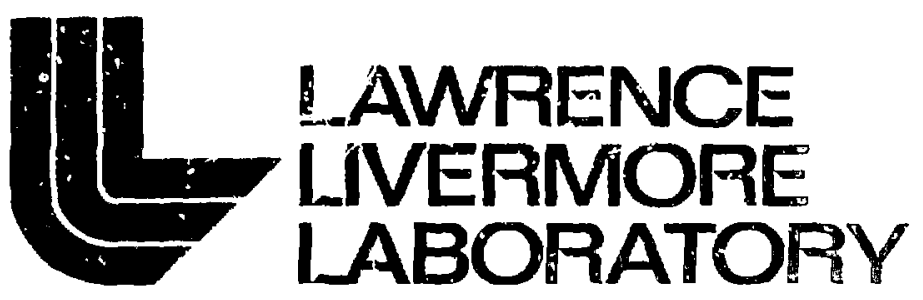

University of California/Livermore

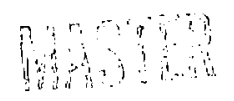




\section{Nottce:}

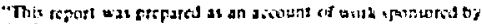

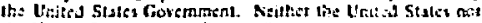

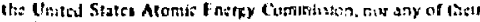

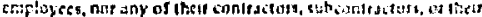

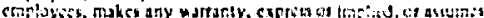

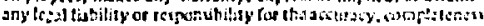

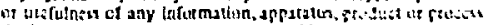

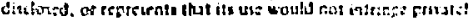
owited rityls."

Printed in the United States of $\Lambda$ merica Available from

National Technical Information Service

U.S. Department of Cornmerce 5285 Port Royal Road

Springfield, Virginia 22151

Price: Printed Copy $\$[$; Microfiche $\$ 0.95$

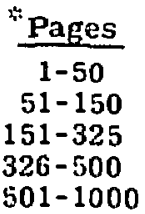

NTIS Selling Price
84.00
$\$ 5.45$
$\$ 7.60$
$\$ 10.60$
$\$ 13.60$ 


\section{노 \\ LAWRENCE UVERMORE LABOAATORY

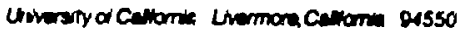

[ CRL-5150!

\section{RIO BLANCO ELECTRONICS}

O. H. Krausc, J. B. Carson, M. F. Iaroska,

S. J. Spataro, and G. E. Bussell

MS, date: April 8, 197.1

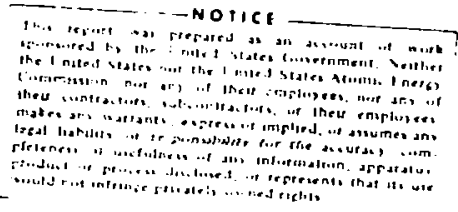




\section{Contents}

Abstract

Intraduction

Integrated Control System

Description

Degign Changes from Miniata

System Test

Compatibility and Certification Testing

Final Checkout and Assembly

Field Operations

Safety Program

Design

Fielding

Arming and Firing Cable

Explosive Verification

Results

Spall Measuremento Program

Downhole Canistera

Accelerometer System

Velocity Gage System

Summer-Mlxer

Remote Surface Stations

CLIPER System

Trailer 68 Instrumentation

Downhole Caniater Signals

C LIPER Signals

Additional Instrumentation

Wellhead A scelerometers

Trailer Response Accelerometer

Water Well Pressure Measurementa

Discussion and Results

Downhole Measurements

Wellhead Accelerometers

Trailer Response Accelerometer

USGS Instrumentation

Problem Areas

Crosstalk B.ptween VCOB

$C$ anister Failures

Fire in Trailer 68

Power Drop Out at Shot Time

Velocity Gage Sensitivitiea 


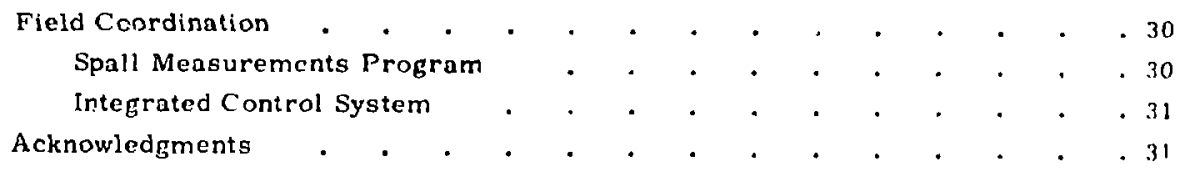




\title{
RIO BLANCO ELECTRONICS
}

\begin{abstract}
The Electronics Enginees: at Department was responsible for the Integrated Control Sysiem (ICS) and the spall measurements program on the klo Blanco Event.

The ICS, consisting of a Control Point, Integratad Control Elcment, and the downhole system in each ranister, was a modifted version of the onn used in the Miniata Event. After testirg, assembly, sud fielding, it performed s iccessfully. The arming and firing cable was able to

withstand scuere environmental conditions and was novel in that it went through the explosive canistors rather than along the side of them.

Spall was measured with CLIPER cables and 20 instrument canisters placed at a variety of locations both above and below the surface. The canisters contained various combinations of acceler. ometers and velocity gages. Spall was detected at all surface stations except one and at depths to $107 \mathrm{~m}$.
\end{abstract}

\section{Introduction}

The Rio Blanco Event (May 17, 1973 ) was an underground experiment ir which three nuclear explosives were detonated simulizneously in the sar. emplacement well in order to increase the permeability of gas-bearing rock (see Fig. 1). The purpose of the project, carried out in Rio Blanco County in western Colorado, was to stimulate natural gas production. Three Diamond explosives, each with a nominal yield of $30 \mathrm{kt}$ were detonited at depths of 1780,1900 , and $203: 1 \mathrm{~m}$.

This report describes the rol, of the Electronics Enginecring Department in the Rio Blanco Event. The department was responsible for the Integrated control System, safety program, spall meas urements program, arming and firing cable, and explosive performancc verification. The geographical layout of the electronics systems is shown in Fig. 2. 


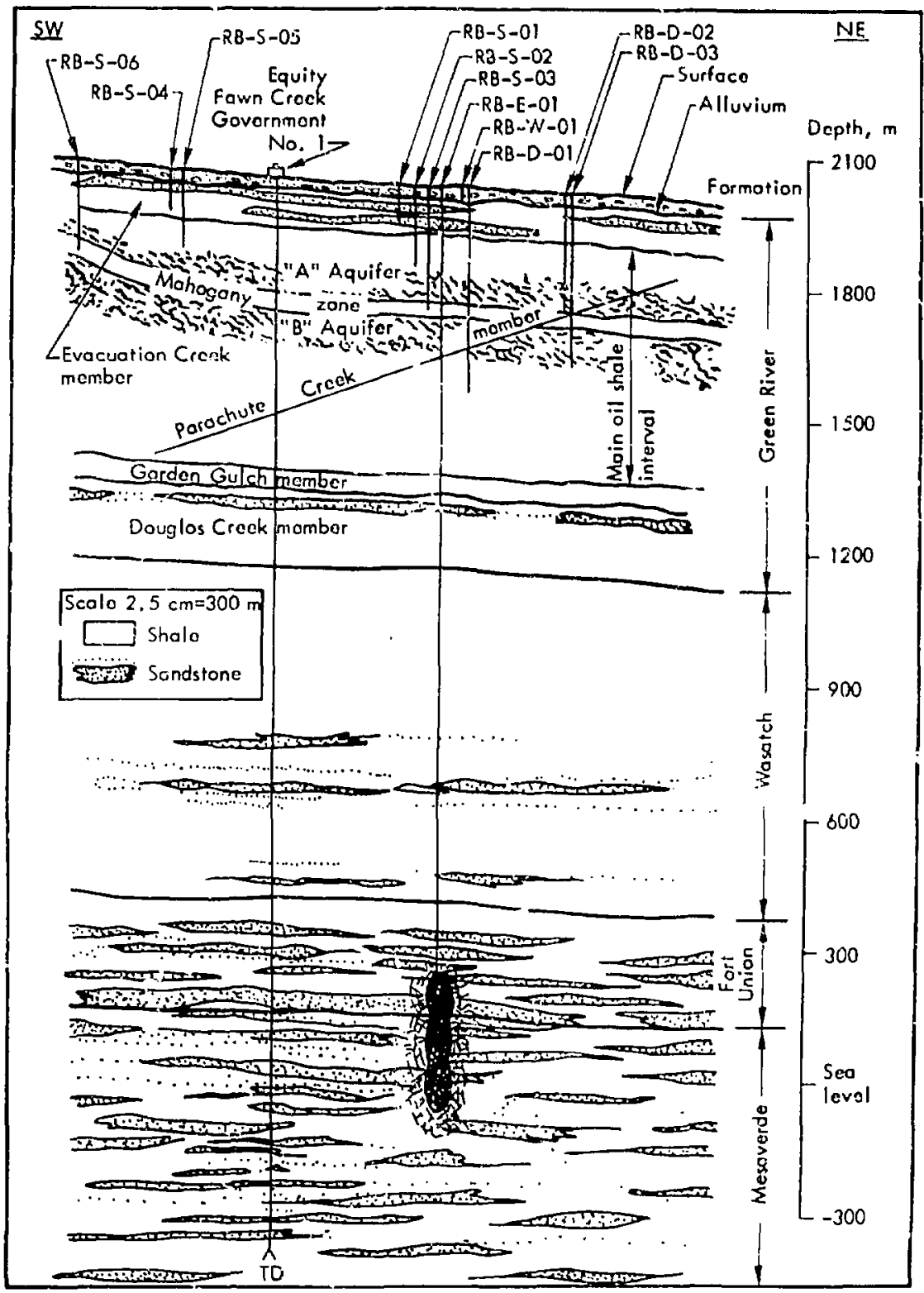

Fig. 1. Geologicai section of the Rio Blanco site. The holes that were drilled for the experiment (i.e. RB-S-01) and the original exploratory well (Equity) are showr. 


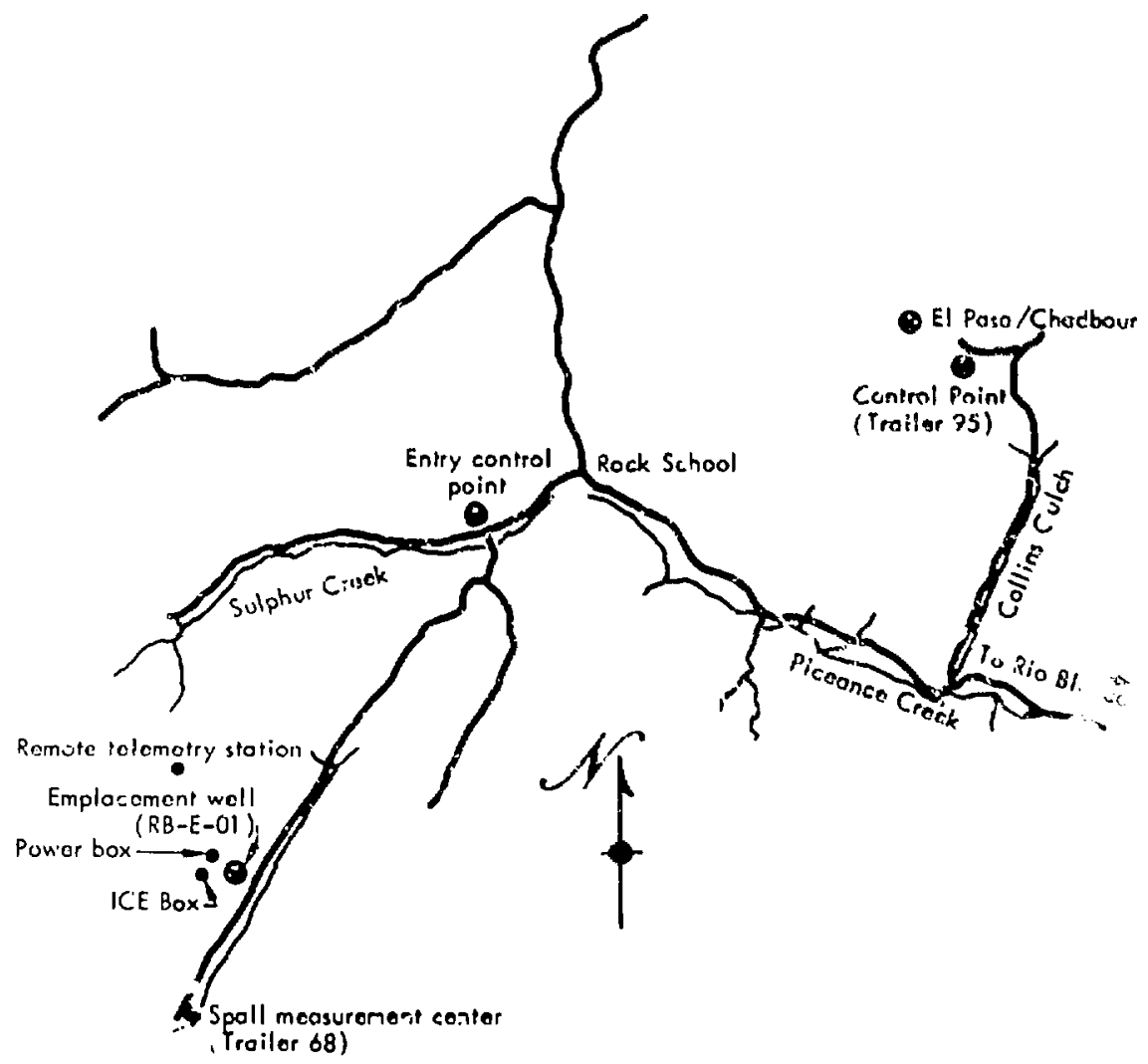

Fig. 2. Map slowling the locntions of the various electronicg installations.

\section{Integrated Control System}

The Integrated Control System (ICS) was used to conduct all remote control and monitoring functions on the Rio Blanco Event. This section summarizes the ICS concept. design, evaluation, assambly. and fielding for Rio Blanco.

\section{DESCRIPTION}

Three major elements make up the ICS (see Fig. 3): the Control Point (CP) located in Trailer 95 , the Integrated Control Element (ICE Box), and the downhole systen: contained in each explosive canister.

The :.P (see Fig. 4) contained the following equipn.ent:

- Control cor:zole from wnich commands were manually or automatically transmitted to the emplacement well (EW) area and on which ICS monito- information $w$ as disi layed to indicate the condition 


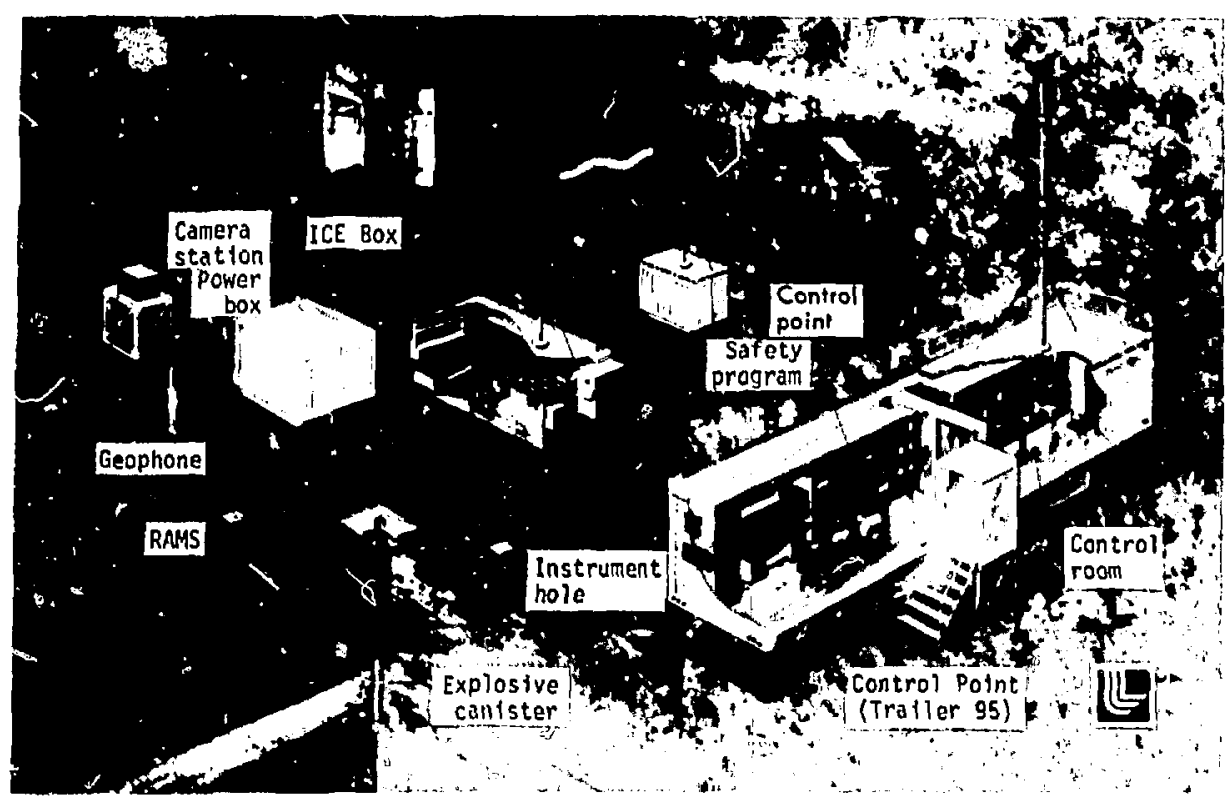

Fif. 3. The Integrated Control System.

of each explosive, the IC:E Box, and related EW-area equipment.

- Safety program data displays for weather, remote area radiation monitoring, seismic, and other related information.

- Microwave equipment for data transmission and communications.

The ICI: Box was the emplacement well terminal of the ICS. It distributed the commands from the $\mathrm{CP}$ dowrihole to the explosives and to close-in surface installations, provided power to the sxplosives, and transmitted monitor information from the explosives, ICE Box, and safety program equipment to the CP. Also, the ICE Hox contained oscilloscope $s$ to record explosive performance data. The ac power to the ICE Box was suppliwd from two, redundant, diesel-electric generator sets with automatic switchover (the Power Box in Fig. 3). In the event of failure of either generator set, the remaining set could handle the entirc ICt: Box load. $T h=$ complete installation is shown in Fig. 5.

Communications and command and monitor information were transmitted between the $\mathrm{CP}$ and the ICF Box by micsowave radio. The microwave links were dual redunciant with automatic switchover in the event of iailure of either link. A single coaxial cable transmitted all power and command and monitor information between the ICE Box and the explosive canisters. On the Rio Blanco Site, the closest line-of-sight path between the CP and the EW area passed approximately $244 \mathrm{~m}$ from the ICE Box location (see Fig. 2). Because of this, the microwave 


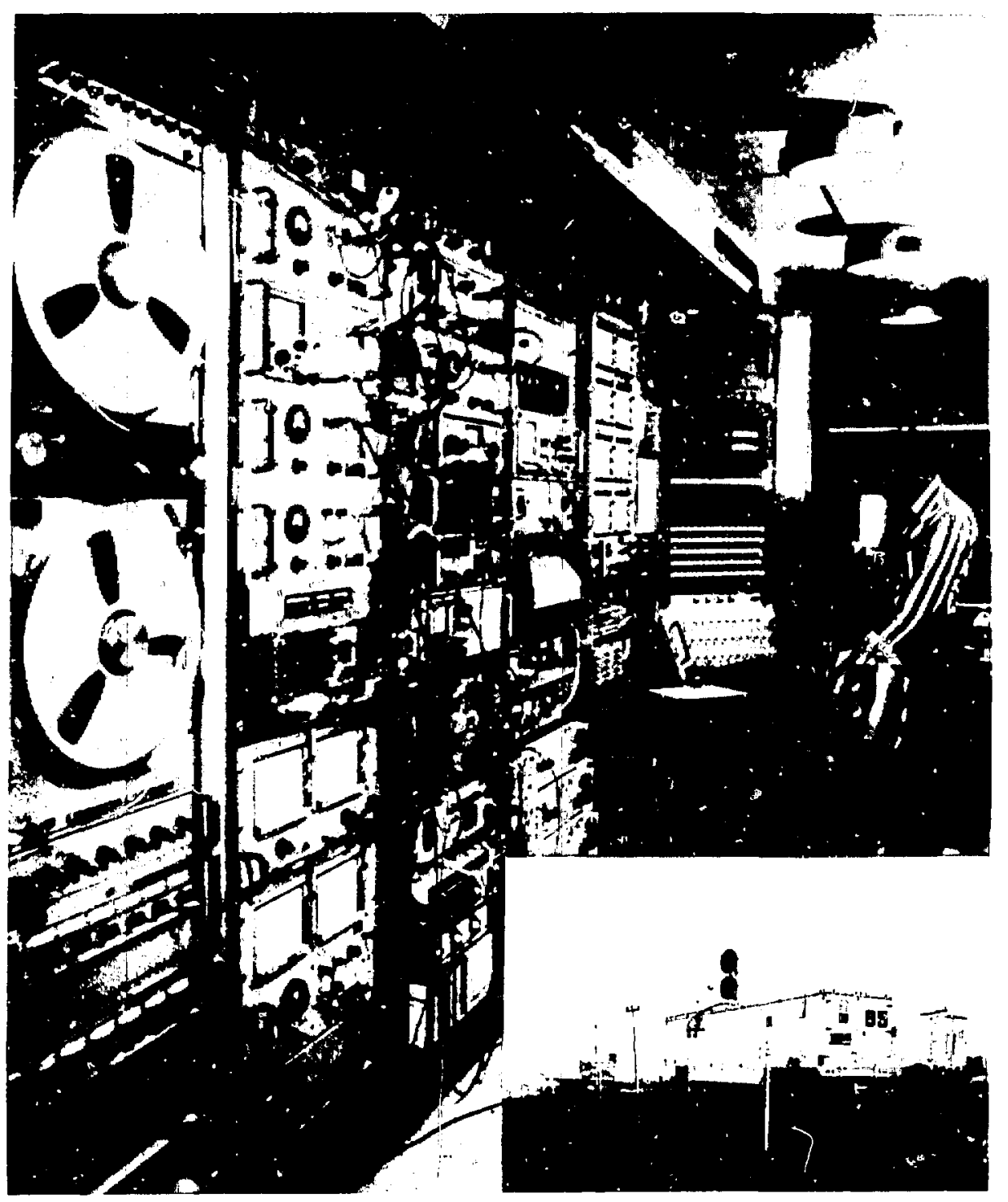

Fig. 4. Trailer 95, the Control Point. 


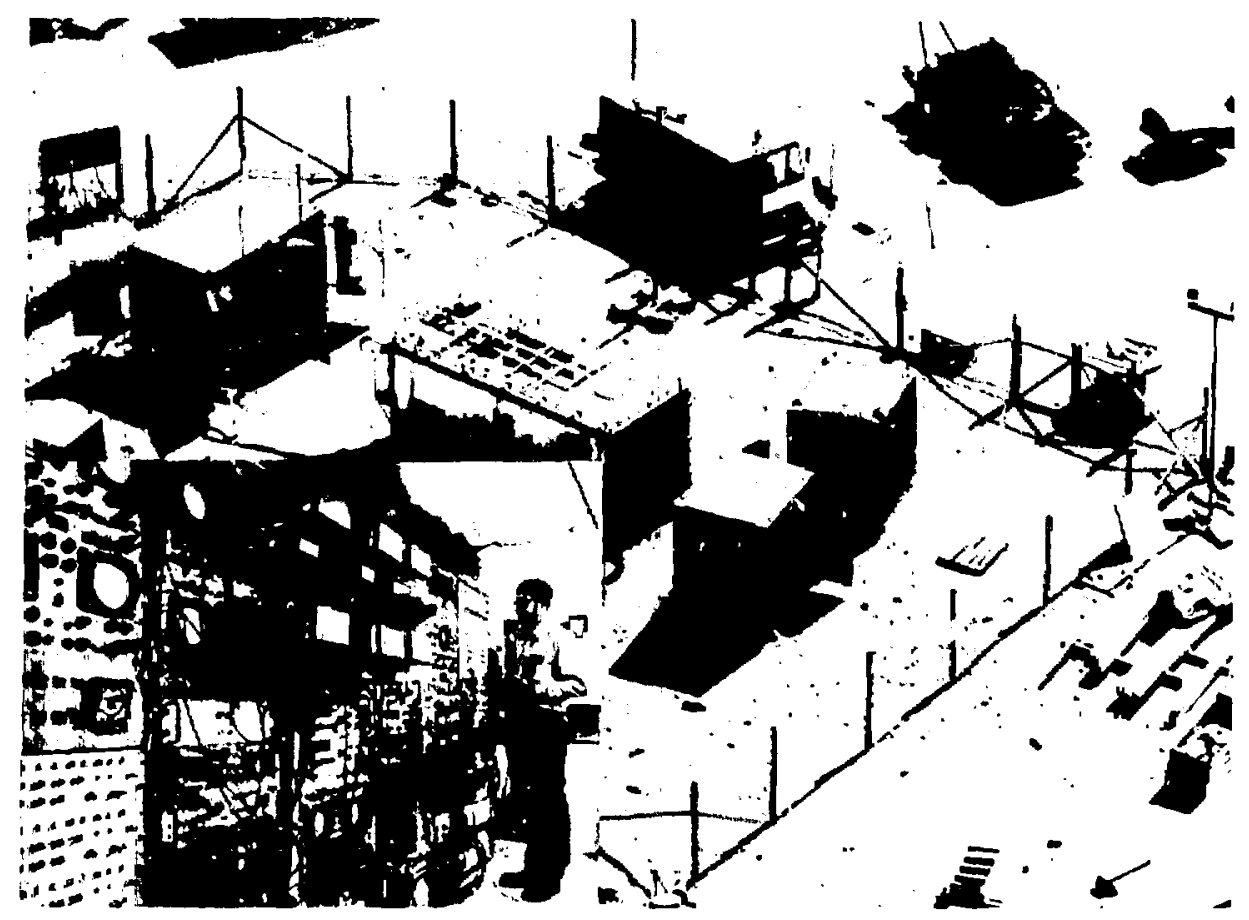

Fig. 5. The ICE Box installation.

equipmelat normally contained in the ICE Box was placed in a small transportainer (the Remote Telemetry Station or RTS) which was located on the EW/CP line-ofsight path (see Fig. 6). Communications and data were transmitted between the ICE Box and the RTS by coaxial cables. The ac power was supplied to the RTS from the Pov'c, Box, The RTS is normally operated as a microwave relay ststion when there is no line-of-3ight path between the CP and ICE Box (Fig. 3).

The downhole system in each explosive canister contained a command decoder, a monitor system, and a power supply (see Fig. 7). In addition, each explosive con- tained a coded switch which interrupted the arming and firing signals between the command decoder and the arming and firing components. The coded switches were closed, from the CP, just prior to the final countdown.

\section{DESIGN C:FANGES FROM MINIATA}

\section{The ICS design for Rio Blanco was} similar to the design used in the Miniata Event, which occurred in July 1971 at the Nevada Test Site (N1S). The Miniata Event was the proof est of the Diamond explosive that was specifically designed for Plowshare gas stimulation applications. 


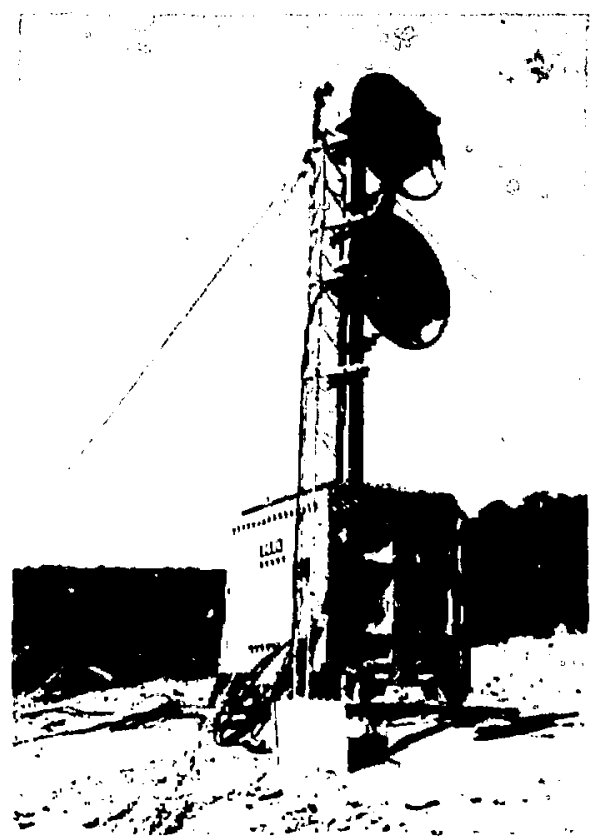

Fig. 6. The Remote Telemetry Station used to relay microwave signals from the [C.E Box to the Command point.

The ICS design changes for Rio Blanco were as follows:

- The single explosive design used on Miniala was adapted to a system capable of handling multiple explosives. This adaptation included:

a. Provision for the multiplexing of the monitor data from the three explosives onto the single cable and the de-multiplexing of this data in the ICE Box and CP.

b. Provision for pulse firing of the explosives to permit the explosives to be fired at nominal $10-\mu s$ interals starting with the bottom explosive. This delay between detonations was needed to allow the recording of explosive performance data from each explosive in scquence in the ICE Box and docs not significantly alter the atmultancous nature of the explosions.

Pulsc firing was necded becausc the normal ICS command system has a jitter in the decoding of commands of plus or minus one cycle of the command subcarrier (165 kHz) which ls equivalent to plus or mims $6.06 \mu \mathrm{s}$. Under normal circumstances this fittcr is of no consequence.

The downhole monltor eysiem for cach explosive was changed from a 20 channcl digital (go-no-go) systam to a 27 channel analog system. The system has an accuracy and resolution of better than $1 \%$ of full scale.

- The rellability of the downhole sys tems was signiftcantly improved by:

a. Reducing the number of components through simplified circuit design. Since each component has a finite failure probability, a reduction in component count improves reliability as long as performance requirements are not compromisad.

b. The use of integrated circuits. The use of integrated circuits improves reliability because their failure probability is much lower than an equivalent circuit made with discretc components.

- The command output board circuit design was changed so that the circuit would fail safe (turn off) if the ground connection to the board became open circuited. In addition, the circuit design was changed to eliminate the need for the 


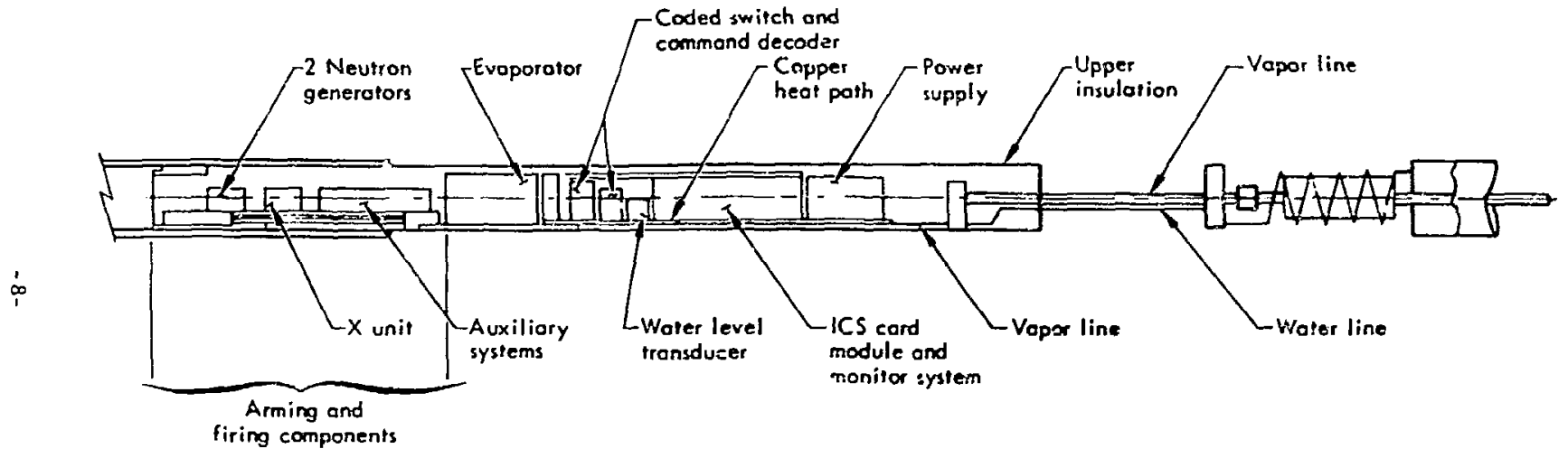

Fig. 7. Schematic of the explosive canister. 
plus and minus $15-1$ power supplies that were required in the provious design.

- The immunity of the command decoder to noise was improved by puectre more atringent requirements on the acceptance of the command word format.

- The power supply circuil changes were as follows:

a. The plus and minus 15-V outputs were deleted.

b. The 3-V output was replaced with a 5 - $A$ constant current cutput for the purpose of charging the $X$-unit. This change was made because the $x$-unit charging requircments are specified un terms of current rather thar: soltage.

c. Scparate 28- ${ }^{\prime}$ outputs werc provided for the command and monitor systems. This prevents a failure that lraws excessive power supply current in either system fion

affecting the other because all of the power supply outputs are individually current limited.

d. The $16-1,3-A$ output was replaced by a capacitor discharge urat for the purpose of firing squib valves and fusc-actuated switches. This was necded io reduce the input 1 . cr surges drawn by the power upply, and thereby reduce the voltage regulation range required due to input voltage fluctuations. The input voltagc Inctuations are caused by the changing input power requirements of the powes supply and the loop resistance of the firing cable to the explosives from the IC $E$ Box. Reducing the range of input voltagc over which regulation is required reduces the internal heat losses in the power supply and therefore improves effictency.

\section{SYSTEM TEST}

A coniplete prototype of the $R$ io Blanco explosive was tested in a 100-ft-decp well in livermore to evaluate its performance under the environmental cenditions in the emplacement well. The well was equipped with a pressurs vessel capable of simulating the expected temperature and pressure environmene $1210^{\circ} \mathrm{F}$ and $5000 \mathrm{lb} / \mathrm{in} .^{2}$ peak pressure during the grouting period and $4000 \mathrm{lb} / \mathrm{in} .^{2}$ formation pressure thereafterl. The ICS was used to measure temperatures, pressures, and ICS functions in the explosive canistar. The temperature and pressure inputs to the pressure vessel were separately recorded.

The first iest started on October 30 , 1972, and ended 12 days laeer dun 10 a malfunction in the cooling system. The necessary repairs and modifications were made and the second test started on December 16, 1972. Although there was a one-weok interruption because of a faulty electrlcal connector on the pres sure vessel, this test was satisfactorily concluded on February 1, 1973, with a simulated countown to verify the performance of the ICS and the arming and firing components after 41 days of operating time. The mechanical engineering aspects of this test have been described.

1. Harri, lawrence Livermore Laboratory, Internal Document COM. 73-69 (1973) (SRD). Readers outside the Laboratory who desire further information on ILl internal documents should address their inquiries to the Technical Information Department, L.awrence Livermore Laboratory, Livermore, California 94550 . 
T:on sygtems test was conducted using the complete lCS in the Rio Blanco configuration so that it could serve as a checkout and dry run for the actual cxperiment. During this test, there was an occastonal malfunction of the microwave recelvers in the ICE Box during the warmup period of the recelvers. This was caused by the fallure of the local oscillator to synchronize through its phase-lock loop to the reference crystal oscillator in the recciver. After a warmup period of about $1 \mathrm{~h}$, the oscillators would synchronize and the receivers would function norially. The symptom during the pariod of malfunction was that the command subcarrier output of the receiver would be strongly modulated ' $y$ and summed with the searih frequency of the phase-lock loop of the local oscillator (approximately 60-80 cycles per second).

The defective signal from the receivers caused the command decoders to decode false commands $w$ ith an address related to valid commands existing in the system at that same time. With no valid commands in the system, no false commands were decoded. In addition, the receiver select chassis, which checks the con:mand subcarrier to decide if either redundant command link is functioning properly, failed to prevent the defective signa: from being transmitted to the command decoder. The false command problem was carefully analyzed and a three part solution was implemented. The solutions were:

- The logic of the data-validity board in the command decoder was changed to prevent the decoding of talse commands due to noise-modulated signals.

- The receiver select chassis was redesigned to reject noise-modulated signals: thereby, preventing such signals from being transmitted to the command decoders.

- New local oscillators that do not have this characteriatic fatlu re mode were purchased for the microwave recelvers.

\section{COMPATIBILITY AND}

CERTIFICATION TESTING

The compaibility and certiftcation tests for the ICS and the Arming and Firing (A\&F) system were concheted at the Sandia Liverriore Laboratory. I. P. Johnson and $W$. L. Lemmc:s of Organization 9132 (A\&F Systems Division) Sandia Albuquerque Laboratory were responsible for the $A \& F$ system and represented Sandia at these tests.

During initial testing, wh, $=h$ started in October 1972, no incompatibilities were found between the ICS and the A\&F system. Although the overall performance of the ICS and $A \& F$ system was satisfactory some apparint problems in the ICS were noted. These problems and their solutions were:

- The delay-output board, which was responsible for the pulse firing of the explosives, was putting out a double trigger to the Sandia fire Pulse Capacitor Discharge Unit (FPCDI). The delayoutput board is triggered by the fire pulse from the ICE Box which in turn triggers the FPCDL, Since the first pulse from the delay-output board triggered the FPCDU at the proper time and the second pulse had no effect, this situation did not constitute an operational problem. This situation was traced to transient feedback within the delay-output boaid from output to input. The feedback was caused by a 
combiuation of the fast switching time of the output transistor on this board and the large capacitive load presented by the input trigger circuits to the FPCDU. This combination produced large peak iransient currents which fed back to the input of the board causing it to trigger a sccond time. The situation was corrected by slowing the switching time of the output transistor with negative capacitive feedback.

- On the first dry run at the expected dowrhole operating temperature $\left(140^{\circ} \mathrm{F}\right)$. one ICS downhole system falled to produce an arming current into the fire set. This problem was traced to a fallure of the command-output board which controls this function. A diode was found to have failed open-circuit. This diode is an established-reliability component and is operated at well below rated stress levels and its failure can only be attributed to either mechanical stresses caused by handling and soldering or random fallure. This board was replaced with an identical board, which operated satiofactorily through the detonation.

- After the ICS downhole systems had been soaked at temperaiure for approximately $48-h$ and 20 dry runs, one ICS downhole system began to trigger the FPCDU prematurely.

This problem was traced to an intermittent switching action of the $28-V$ delay board that was caused by induced voltage from an adjacent board (frequency separator I). The $28-\mathrm{V}$ delay board delays the application of $28 \mathrm{~V}$ to the command-output boards until the $5-\mathrm{V}$ logic circuits have stabilized after the application of downhole power. The command output boards, when addressed by the appropriate command, gato the $28-\mathrm{V}$ power through to perform the command functions. By its intormittent awitching Bction, the $28-V$ delay board was gating on and of the actlve commands. This problem was eliminated by bypassing high source impedance vollage reference points with capacitors to shunt the induced voltage to ground. This provided the stable dc reforence voltages necessary for the proper functioning of the circuit.

- One ICS downhole Byotem occasionally produced apurious ratchet pulses to the coded switch when all commands were dropped at the end of a dry run $(+2 a)$. This problem was sraced to an inductive voltage trangient reflected from one of the Sandia, fire-set simulators back into the ICS downhole system. The defective transformer in the fire set simulator was replaced. In addition, capacitors to ground were placed on the output of each of the arm current power supplies to minimize the effect of reflected transients on the ICS system from the fire sets.

- Later, a delay-output board was found to be producing a spurious output at the end of dry runs when all commands were dropped. This was traced to a cause similar to the previous item. The arm-enable relay was opening before the reflected, inductive-voltage transient from the fire-set simulator could be bypassed to ground by the capacitor on the output of the arm-current power supply. The solution to this problem was to delay the dropping of the arm-enable command until one second after all other commands were dropped, thereby leaving the bypass capacitor to ground in the circuit unt 11 the inductive transient was dissipated. 
After the previaualy mentioned problems werc resolved, testing was resumed. A null-scale certification test with live A\&F components was conducted in December 1972. Due to a malfunction of the camera shutter actuation system, no oscilloscope data was recorded. Streaking camera data showed that all the ARF components performed satisfnctorily; however, no analog output data was obtained from the neutron generators. A second certification was run in January 1973 in which all data was successfully recorded.

During this test berias, the ICS downhole systems were operated from the dry run rack and through the Rochester" (see Arming and Firing Cable) cable, which Included jumpers of the approprlate length to interconnect the threa systems. The downhole systems were maintained at $140^{\circ} \mathrm{F}$, the maxinum expected temperaiure. The dry-run rack contained, in a portable double width relay rack, equipment identical to that which was used in the CP traller and the ICE Box.

\section{FINAL CHECKOUT AND ASSEMBLY}

The final checkout and assembly of the Rio Blanco explosives took place in two parts. The downhole ICS system, auxiliary system, A\&F system, and the evaporator for cooling system were assembled in Livermore. The ICS and the A\&F systems were checked for proper operation during several dry runs. Also, the pressure and temperature channels

Reference to a company or product name does not imply approval or recommendation of the product by the University of California or the U.S. Atomic Energy Commission to the exclusion of others that may be suitable. for ench of the downhole monitor systeme were calibrated at that ime. The checkout and calibration was performed through the entire ICS including CP traller, microwave link, and ICE Box. Thls phase was completed in January 1973.

The final assembly took place in the 410 area at the NTS. The ICS dry-run rack was used to complete this part. The downhole systems were checked out through both the Rochester and RF-1 (see Arming and Firing Cable) ilring cables so that either cable could be used for the actual detonation. The last electrical system checks were then completed and the final coje set into the coded switches.

\section{FIELD OPERATIONS}

We started work at the Rio Blanco site on Monday, April IC, 1973. By the following Saturday, April 21, the ICS was set up, checked out, and ready for the delivery of the explosives. There were three dry-run ICS downhole systems and three A\&F system simulators in the ICE Box to simulate the actual downhole systems. These were used to check out the ICS. The dry-run ICS downhole systems were identical to the actual systems except that they did not contain high reliability parts. In addition to checking the A\&F signals from the ICS downhole systems, the A\&F system simulators fcd simulated pressure and temperature data into the ICS to check out the monitor systems.

Before the explosives were unloaded from the shipping van, an explosive system check was performed on all three systems. The explosives were then removed from the shipping van, the external 
cooling system components nttached, and the downhole operation started. Firgure 8 shows the emplacement rif and shipping, van, At various times during the downhole and stemming operations and up to the final detonation, explosives systems checks were performed, The purpose of the systems check was to verify the performance of the power supplies, command decoders, monitor systems, and the integrity of the explosives. The status of the coded switches and other downhole monitors was verified and pressure and temperature data were recorded. These checks were marle two to four times a day depending on the rircumstances.
The explosive systems check procedure was as follows:

- ICS performance was verified through the dry-run systems and $A \& F^{\prime}$ stmulators.

- Power was applled to the explostves.

- The downhole monitor status was verified.

- The test command was transmilled and recelpt was confirmed through the monitor syatems. The test command scrved to verify the performance of the downhole command decoders. It performed no other functions; therefore, safety requirements were not compromised.

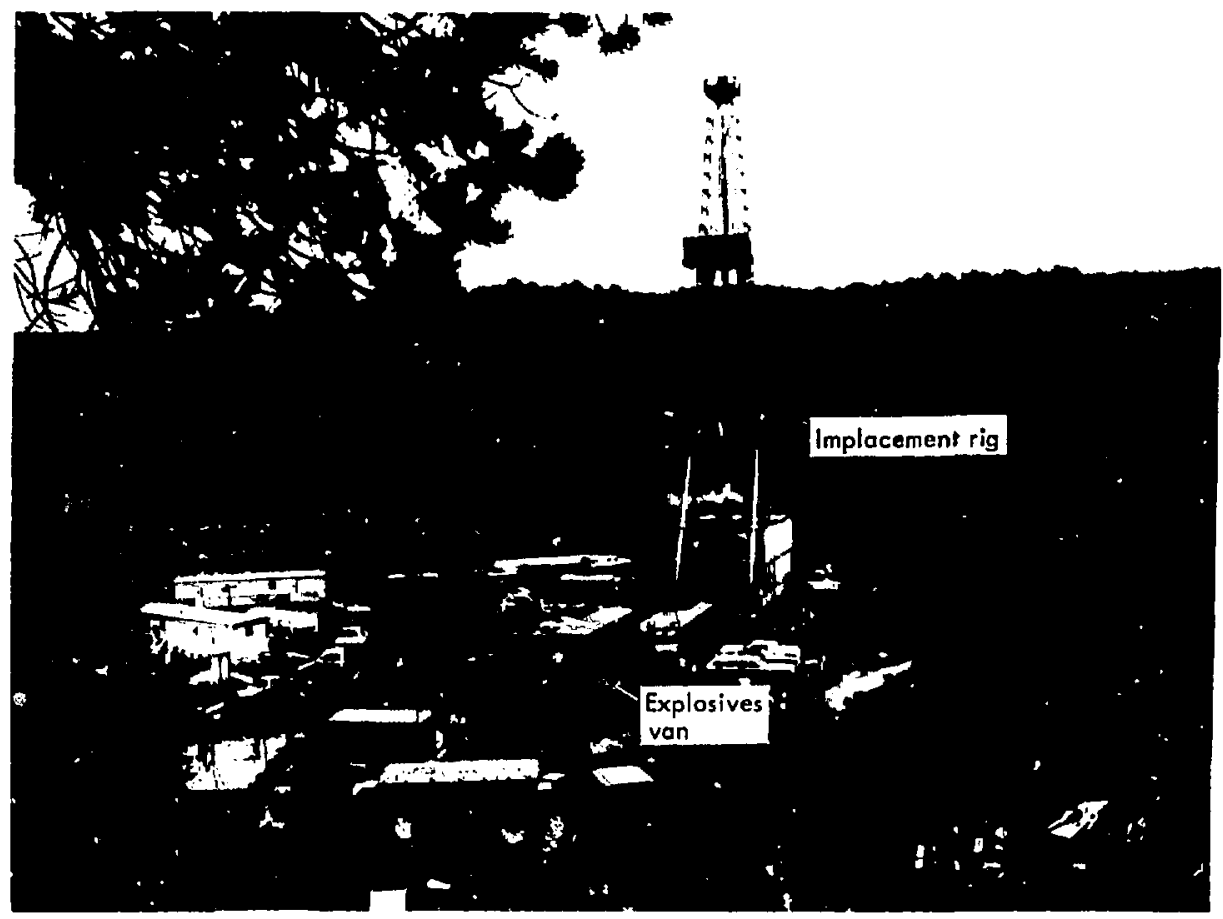

Fig. 8. Photograph of the site showing the emplacement well and the van tisid to transport the explosives. 
- Pressurc and temperature da:a from the explosives were recorded.

After the explosives were at the bottom of the emplacernent well, but before stemming operations werc initiated, it was noticed that the test command was intermittently decoded in the top explosive during a systems check. The command system utilizes a digital format that is composed of a series of "ones" and "zeros" coded into pulses of stfferent widths in time sequence to denote a particular command. The width or time duration of a "one" is double the width of a "zero." The logic of the command decoder is designed to prevent the decoding of false commands from elther a noisy signal, an invalid command forr iat, or a combination of both. This is very important for safety reasons. One of the checks perfornied on the command fcrmat by the decoder is the width of the "zero" bitg. The "zero"bit width detector is set to reject bits with widths less than 90 : of the normal value.

The intermittent decoding of the test command was caused by a drift in the bit widths of the commann generator in the CP comblned with a probable change in the set range of the downhole bit width detector in the top explosive due to the duwnhole temperature. Adjusting the zero bit width in the command generator to the proper value solved the problem.

Mandatory dry runs for all technical program parilcipants we re held on the fifth and the fourth days preceding the detonation. The total time in the ileld for the ICS detonation service was five weeks from the initial set-up and checkout of the system through the sccuring of the system for shipment back to Livermore. The ICS field crow consisted of four electronics engis..ers, two esectronics technicians, and onc electronics coordinator.

\section{Safety Program}

The ICS contained a remote area monitoring system (RAMS) to detect and monitor radioactive gases that might escape from the emplacement well, an air analyzer to detect radioactive particulates, and geophones to record postshot seismic activity.

\section{DESIGN}

The safety equipment was first tested on the Miniata Event both as a backup for for the NTS safety system and as a dry mun for Rio Blanco. The compatibility of the sdfety program equipment with the
ICS monitor-telemetry system was studied after the Miniata Event and the system parameters were defined. Subsequently, the equipmem was modified or redesigned to conform to a 0 to $+5 \mathrm{~V}$ high-input impedance $(1 \mathrm{~m} \Omega)$, a low output impedance $\langle 100 \Omega$, and a $250 \mathrm{~ms}$ per channel sampling rate. The modified equipment Cor Rio Blanco was tested by Hazar Control and Eberline Instruments personnel during the system test.

Reservations weie expressed about the interpretation of the geophone signals because of the sampling rate and the unipolar monitor system. The geophones 
normally produce a btpolar mutput and operate above their resonanci? frequency, which was about 1.0 cycle per second for the chosen units.

The geophone system was expected to perform adequately while the RAMS and weather Instruments were expected to perform well. Prior to flelding the equipment, current and voltage limiting for electromagnetic pulse (TMP) protection was adided, even though it was felt that FiMp would not be a problem with the Ris Blanco configuration.

\section{FIELDING}

During the installation of the RAMS, the readout equipment gave a hlghi bnck ground reading when the monitor inputs

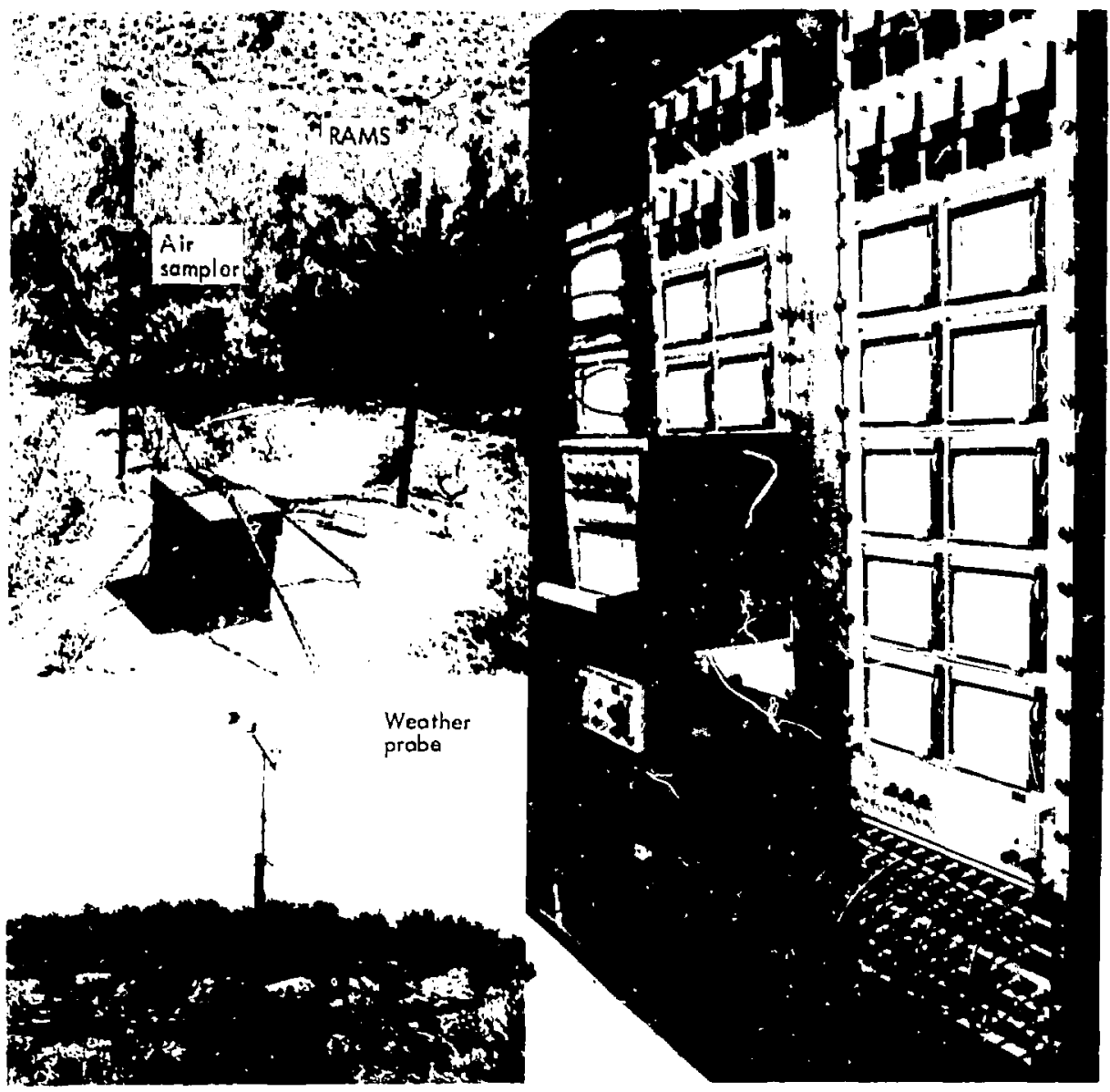

Fig. 9. The detectors and control room used to monitor radioactivity and weather conditions. 
were open. This situation was unacceptable. After installation and checkout c) the geophone system it became necessary to amplify the signal level and provide voltage offset to properly transmit the bipolar output of the geophones over the usipolar monitor system. The wind speed sensing head required modi- fication to function properly with the long cable between the sensor head and the translator. The Hazards Control sensors and control room are shown in Fig. 9. The safey program equipment required only minor field modifications to achieve the deaired operating characteristice. and performed very successfully.

\section{Arming and Firing Cable}

With the development of the single cable ICS it became necessary to develop a coaxial cable and a flat cable of equal impedance to meet all anticipated conditions. The worst foreseeable environment for the coaxial cable vas a mud flled, uncased, 6100-m-deep hole with a temperature of $205^{\circ} \mathrm{C}$ and a pressure of $70 \mathrm{MPa}$. To meet these conditions the spectfications called for a doublearmored, fully gas blocked, 30- to $50-\Omega$ impedance cable with a loop resistance of less than $3 \mathrm{a}$ per $1000 \mathrm{ft}$, to operate at $205^{\circ} \mathrm{C}$ and $70 \mathrm{MPa}$. These specifications were sent to 34 cable manufacturers, Proposals were received from five. Orders for prototype production were given to the three lowest bidders, but the only prototypes recelved in time were from Rochester Cable and US Steel. The Rochester cable used Tefzel as a dielectric material to meet the temperature requirement an' 3 met all the electrical and impedance requiremrats. However, it failed the gas hlocking tests and the $205^{\circ} \mathrm{C}$, 70-MPa requirement. At that temperature and pressure the Tefzel started to crack. Succeeding tests showed that the cable was good up to $150^{\circ} \mathrm{C}$ and $49 \mathrm{MPa}$, which was well within the requirements for Rio Blanco $\left(120^{\circ} \mathrm{C}\right.$ and $35 \mathrm{MPa}$ ).

The US steel cable met all specifications except those of the tinse-domain reflectometry (TDR) tesis which showed a 1.5- $\Omega$ impedance varialion every $10 \mathrm{ft}$. Thls was due to a cyclic variation in the dielectric thickniss. United States Steel did not have any solution to this problem. Since time was a critica' factor at this polnt and a 50- $\Omega$ irmpedance was needed. the cable order went to Rochester.

Rechester contir 'sed looking for an acceptable gas blocking compound, but all our tests indicated gas leakage. Most tegts were performed at ambient temperature and pressure. Then it was decided to simulate the effect of pressure on the cable. A piece of cable was grouled at $21 \mathrm{MPa}$. After grout setup, the pressure was released and the gas-blocking test repeated. A 200-fold decrease in the leak rate was observed. It was thought that the effects of temperature and continued pressure on the cable might result in an even greater improvement.

When the event as suddenly delayed by six months, it was decided to test a stand ard RF-1 cable (gas blocked) at $120^{\circ} \mathrm{C}$ and $35 \mathrm{MPa}$. This test was 
successful and a special order was placed to double armor a Rli-1 cable for use on Rio Blanco. In the meantime the Rochester $c$ able was used for the certification tests at the Sandia Livermore Laboratory,

After receipt of the armored RF-1 cable, it too was tested at temperature and pressure, while terminated in the appropiriate downhole Advanced Systems Engineering (ASE) connector. After a few days at temperature and pressure the electrical resistance between the center conductor and the shicld of the cable showed a slow but steady decrease. The test was stopped and examination of the connector showed that somc of the gas blocking crompound from the stranded center conductor had been extruded into the connector. Chemical analysis showed the presence of titanum oxide which becomes conductive in the presence of even very small amounis of water.

At that time it was decided to make the final explosive assembly and checkout at Nevada with both the Rochester cable and the RF-1 and simultaneously initiate another test to see if the cable termination could be improved to eliminate the extrusion of the gas blocking compound into the connestor.

Both cables were then sent into the field while the RF-1 test was repeated. When the results of the second test were essentially the same as before it was decided to use the Rochester cable for
Rio Blanco. The Rochester cable was used successfully and showed no postshot gas le.ikage.

In the early planning stages it was assunied that tha $20.3-\mathrm{cm}$-diameter explosive could and would be emplaced in a $24.5-\mathrm{cm}$ casing. This left very marginal clearance for a double-armored cahle. The better and safer solution was to bring the cable into the top of the canister and out at the bottom, and on the next explosive. The only problem with this solution was the very limited space $10.15-\mathrm{cm}$ thickness by $1.55-\mathrm{cm}$ in width) available inside the canister and the reed to maintain the $50-\Omega$ impedance. Therefore, it was necessary to develop another speciai cable to link the top and bottom of each caisister.

The first prototype built to our specifi cation for the Mininta Event was a triplate cable, $0.18 \mathrm{~cm}$ by $1.27 \mathrm{~cm}$. Ths cable was electrically satisfictory, but the permissible bending radius was much too large to be useful for our application.

Following Miniata we looked for bids from various flat cable companies, but no one could mect the bending radius requirements for this particular design. Ansley East Company : 'swed the greatest interest in the problem and eventually designed and built a $50-5$ ?, shielded, parallel-wire cable with overall dimensions of $0.15 \times 0.64 \mathrm{~cm}$ that could meet all specifications. This cable uas successfully used in the top two explosives.

\section{Explosive Verification}

Since Rio Blanco was the first gas stimulation experiment to use three simultaneous detonations in the same emplace- ment well, it was decided from the start that a positive verification of detonation of each explosive was essential. It was 
al so decided that the cost of any special explosive diagnostic system had to be kept to the minimum. Previous experience had shown that the easiest and simplest verification comes from the electromagretic signal generated on coaxinl cables during a nuclear explosion. Thus, the perfect solution was to look at the signal from each explosi: : on the arming and firing cable.

With only one cable providing all the power and comnuand signals to the three explosives, the cable had to either run on the outside or the inside of the two top explosives. As previously mentioned in the Rio Blanco cible description, it was decided to run the firing cable on the inside of the explosive canisters to avoid any accidental cable damage during lowerng of the explosives. Since there was no prior experience with the special $0.15 \mathrm{~cm}$

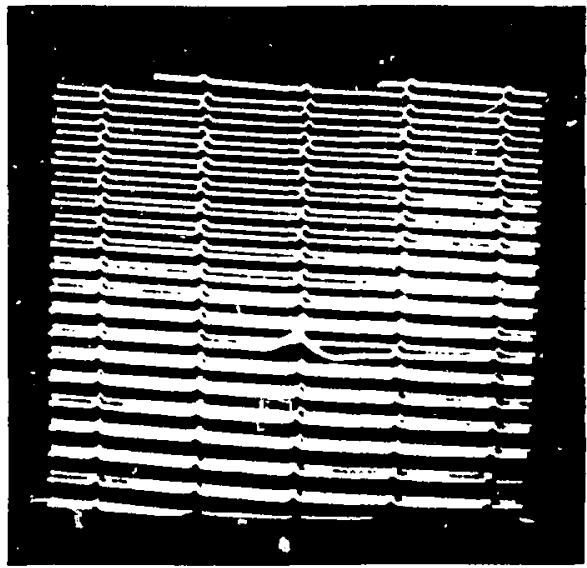

Fig. 10. The diagnostic signal from ihe firing cable. The signal corresponds to the detonation of the upper explosive since the cable was severed in the top explosive before the arrival of signals from the lower explosives.

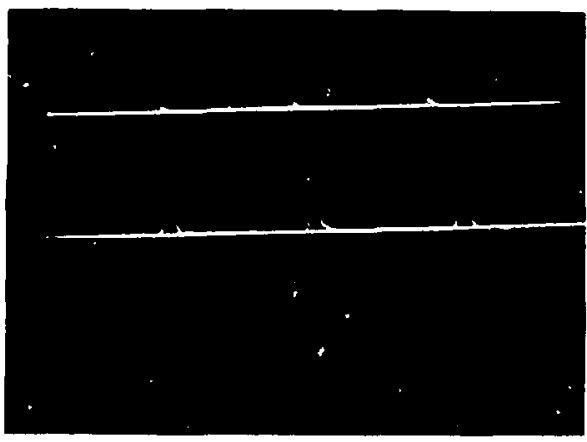

Fig. 11. The response from the RF-1 diagnostic cable. The three signals are from each of the three explosives and are shown with programmed time delay on a dual-trace oscilloscope. The upper trace sensitivity was set for $50 \mathrm{~V} / \mathrm{cm}$ and the lower for $10 \mathrm{~V} / \mathrm{cm}$. The timing wave was $2 \mathrm{MHz}$.

$\times 0.64 \mathrm{~cm}, 50-\Omega$ shielded parallel wire

line on the inside of the explosive canister. it was too risky to rely on the firing cable as the only verification source. Therefore a standard, continuous, unarmored $\mathrm{RF}-1$ cable was run all the way to the bottom of the well alongside of the explosives. This cable eventually served thrce functions: Detonation verification, chimney height information, and with the addition of a passive pressure trinsducer at the end of the cable, the downhole pressure history was recorded during and after the grouting operation.

To see all three explosive signals on the two cables it was nacessary to detonate with some delay from the bottom up.

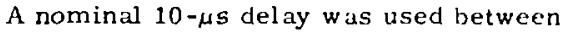
detonations to allow enough time for the signals to pass the other explosives before the cable was cut. 


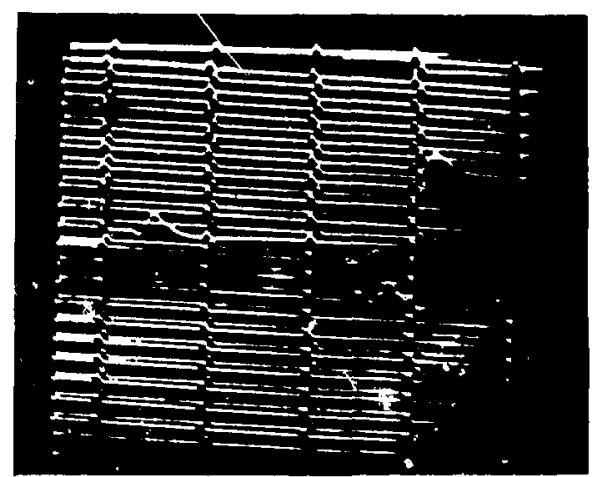

Fig. 12. A different presentation of the response from the RF-1 cable. The pulses were attenuated on a

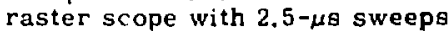
and $0.5-1, s$ markers on each sweep line, The scope retriggered giving the double trace.

\section{RESULTS}

We obtained only the signal from the top explosive on the firing cable (Fig. 10).
This is because the cable was severied in the top e...jlosive before the arrival if the signals from the detonation of the lower two explosives. Fortunately, signais from all three explosives were deteited on the RF-1 cable that was alongside the explosives (see Figs. 11 and 12).

Figure 12 shows the pulses attenuated on a raster scope. The measured signal separation is approximately $8.7 \mu \mathrm{s}$ between detonations. The oscllloscopes were triggered from a delayed fire pulse.

The cable break measurement ylelded the desired chimney height information, recording a break in the RF-1 approxi. mately $335 \mathrm{ft}$ above the top explosive and $a$ break in the firing cable at 150 ft above the explosive. The pressure measurement confirmed the anticipated pressure increase during the grout pumping.

\section{Spall Measurements Program}

The objective of the spall measurement program was to measure the depth and extent of ground spall (tensile failure of the rock) caused by explosion-induced stressfield interactions as the ascending compres sive wave is reflected at the ground surface.

To accomplish this objective, 10 instrument holes ranging in depth from about $4.6 \mathrm{~m}$ to $274 \mathrm{~m}$ were drilled and emplaced with 20 instrument canisters containing accelerometer and velocity gages (see Fig. 13). In addition, five of the holes were instrumented with special CLIPER (Collapse Location Indicator by Pulsed Electromagnetic Reflection) cables. The experiments were all controlled from Trailer 68 (see Fig. 14).

Following is a description of the varlous instrumentation systems used in the spall program, discussion of the data and playback system, and recommendations for futcre fielding operations.

\section{DOWNHOLE CAIISTERS}

All of the spall canisters were identical, with the exception of those at the four surface stations. Each canister contained one Kistler Model 305A accelerometer, one Spartan Model $602 \mathrm{~V}$ velocity gage, 


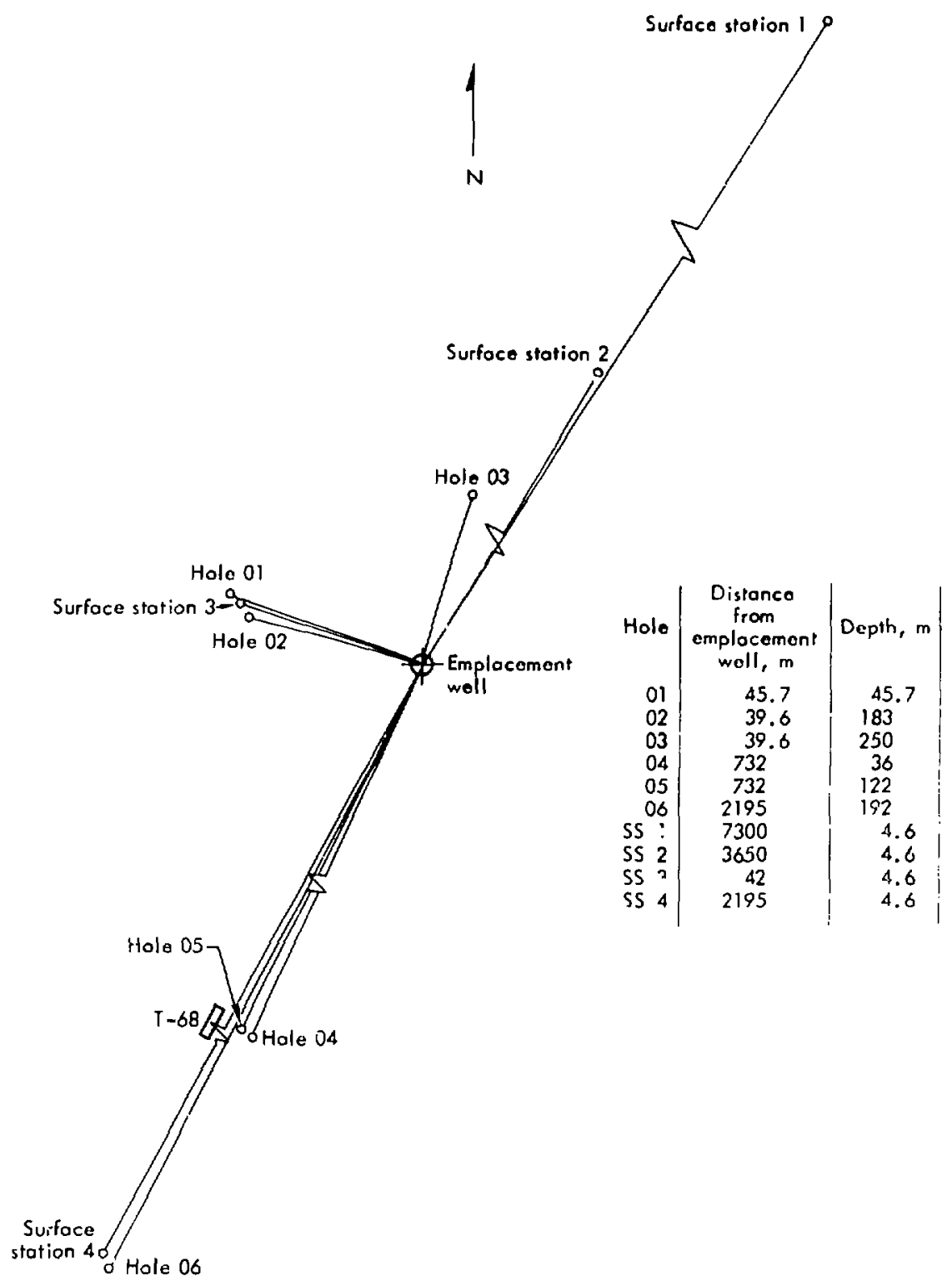

Fig. 13. Locations of the sensars used in the spall measurements program. 


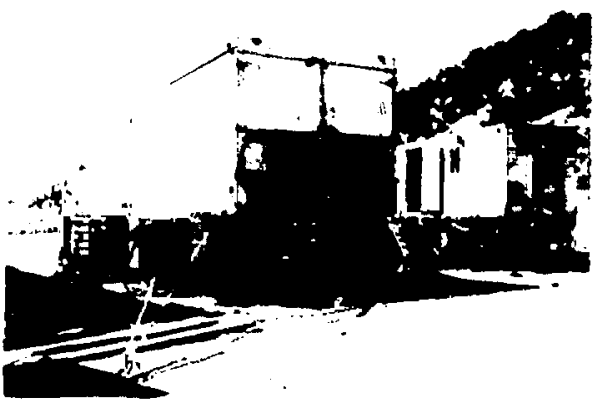

Fig. 14. Trailer 68, the control center for the spali measuraments program.

and appropriate electronics (see the block diagram, Fig. 15). Nso included in the canisters were an explosive guillotine system used to sever the canisters from the downhole lowering cable after emplacement and prior to shot time, and a thermistor to monitor canister temperature.

\section{Accelerometer System}

The accelerometer was mounted in a vertical atistude on a central, removable core within the canister body. Its signal output was delivered in parallel to two, high-input impedance, voltage-controlled oscillators (VCOs), LEA 70-1128, center tuned to nominal frequencies of $300 \mathrm{kHz}$ and $1200 \mathrm{kHz}$. Precision, metal-film resistors at the VCO inputs determined the accelerometer sensitivity (volts per $g$ ). The $300-\mathrm{kHz}$ VCO sensitivity was set so that we could measure the maximum expected acceleration pulses on initial ground acceleration and slapdown. We used a nominal $\pm 15 \%$ feviation of center frequency for full-scale gage range, which was typically 12 to $20 \mathrm{~g}$. System gensitivities for the $300-\mathrm{kHz}$ VCOs were $3-4 \mathrm{kHz} / \mathrm{g}$.

The $1200-\mathrm{kHz}$ VCO sensitivities were established so that a $\pm 15 \%$ deviation of center frequency was again equal to the full-scale gage range, which was $\pm 2.5 \mathrm{~g}$. This resulted in sensitivities of $70-80 \mathrm{kHz} /$ $g$ for these VCOs. The idea was to establish greater resolution when looking at the - 1 g spall levels.

This dual-ranged accelerometer system provided us with a system capable of measuring accelerations from a few tenths of a $\mathrm{g}$ to about $20 \mathrm{~g}$ or roughly a 40-db dynamic range. The $+15 \mathrm{~V}$ and $-15 \mathrm{~V}$ required for the accelerometer operation was taken from the $+15 \mathrm{~V}$ and $-15 \mathrm{~V}$ regulators on one of the VCOs.

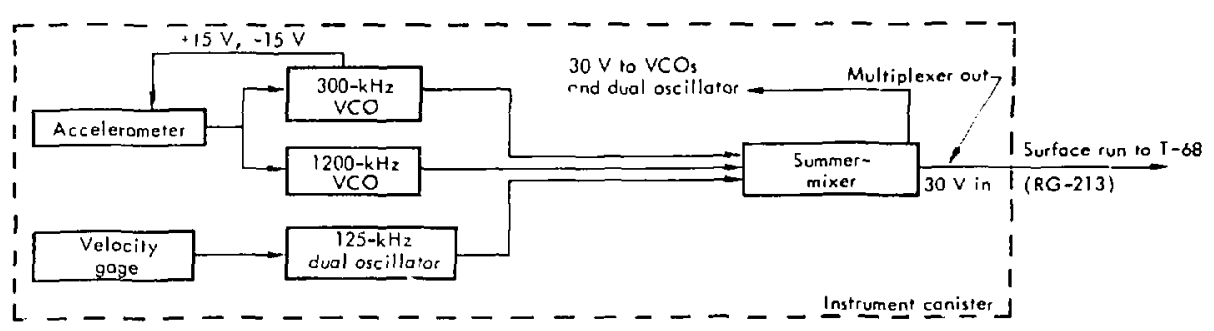

Fig. 15. Block diagram of a typical downhole canister used in taking spall measu rements. 


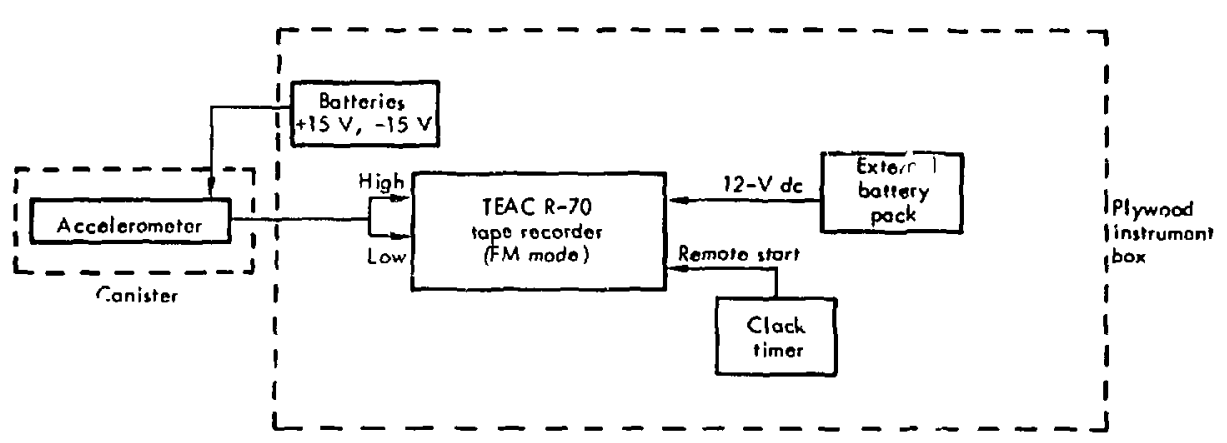

Fig. 16. Block diagram of a remote surface station.

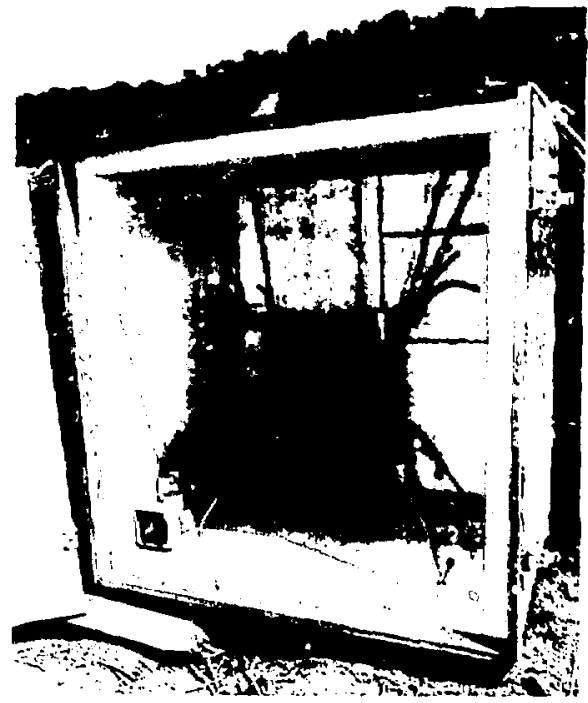

Fig. 17. Tape recorder used to record spall data at a remote surface station.

\section{Velocity Gage System}

The velocity gage was mounted just below the accelerometer. The gage output was used to frequency modul ate a dual oscillator-modulator circuit, LEA 72-1186, which was center tuned to a nominal $125 \mathrm{kHz}$. System sensitivities for the velocity gages were typically 650 to $1000 \mathrm{~Hz} / \mathrm{m} / \mathrm{s}$.

\section{Summer-Mixer}

The VCO and dual oscillator outputs were then delivered to a summermultiplexer, LEA 70-1137. The three summer inputs were low-pass filtered at the 3 carrier irequencies $+15 \%$ with a 6 -pole LC filter. The signals were then combined and delivered through a buffer amplifier to the surface run RG-213 cable via $R F-1$. The dc power for the canister electronics was delivered from Traller 68 down this same cable, through a high pass filter at the summer output, and then distributed to the VCOs and dual oscillaior in the canisters.

The surface canisters at the well-head area and at the $2195-\mathrm{m}$ station were identical to the downhole canister described above, except that they contained only the accelerometer and its electronics. No velocity gage was used

\section{REMOTE SURFACE STATIONS}

The two remote surface stations, at approximately $3.6 \mathrm{~km}$ and $7.3 \mathrm{~km}$ from 
the emplacement well, were arranged differently from the other spall canisters (see Fig. 16). Small 15-V mercury batteries were used to supply power to the Kistler $305 \mathrm{~A}$ accelerometer. The accelerometer sensitivities for the $3.6-$ and $7.3-\mathrm{km}$ stations were $0.5 \mathrm{~V} / \mathrm{g}$ and $1 \mathrm{~V} / \mathrm{g}$, respectively.

The signal output was delivered to two channels of a cassette tape recorder, a TEAC Model R-70. FM mode recording $w$ as used. The signals were dual ranged at a 2:1 ratio so that our sensitivities were increased to $1 \mathrm{~V} / \mathrm{g}$ and $2 \mathrm{~V} / \mathrm{g}$. The recorders were powered from an external battery nack $\{12 \mathrm{~V}$ at $350 \mathrm{~mA}$ ). A mechanical clock timer was used for remote start capability. The tape recorder $w$ as suspended by bungee cord inside a $3-\mathrm{ft}$ cube plywood box to minimize shock due to ground motion (see Fig. 17). At approximately $\mathrm{H}-2 \mathrm{~h}$, accelerometer and tape recorder power was applied, and the mechanical timer set. Recording started at approximately $T$ - 10 minutes. No zero-time signal was applied to the tape.

\section{CLIPER SYSTEM}

Five of the instrument holes contained a special CLIPER cable, which consisted of RG-81 cable (copper jacketed) installed in the grouted portion of the instrument hole and pulsed from its lower end (see Fig. 18). External upsets (circular knobs) were attached every $60 \mathrm{~cm}$ to increase its shear bond to the grout. RF- 1 cable was used to carry pulses downhole to and from the lower end of the RG-81. A CLIPER pulser, LEA 72-1087, was used to send (and receive) a pulse train to the CLIPER cable system. The pulser acted as a triggerable multivibrator so that the pulse repetition (requency (PRF) was a function of total cable length. The system was capable of a resolution of a meter in several thousand, and would detect either a short or ofen in any part of the cable.

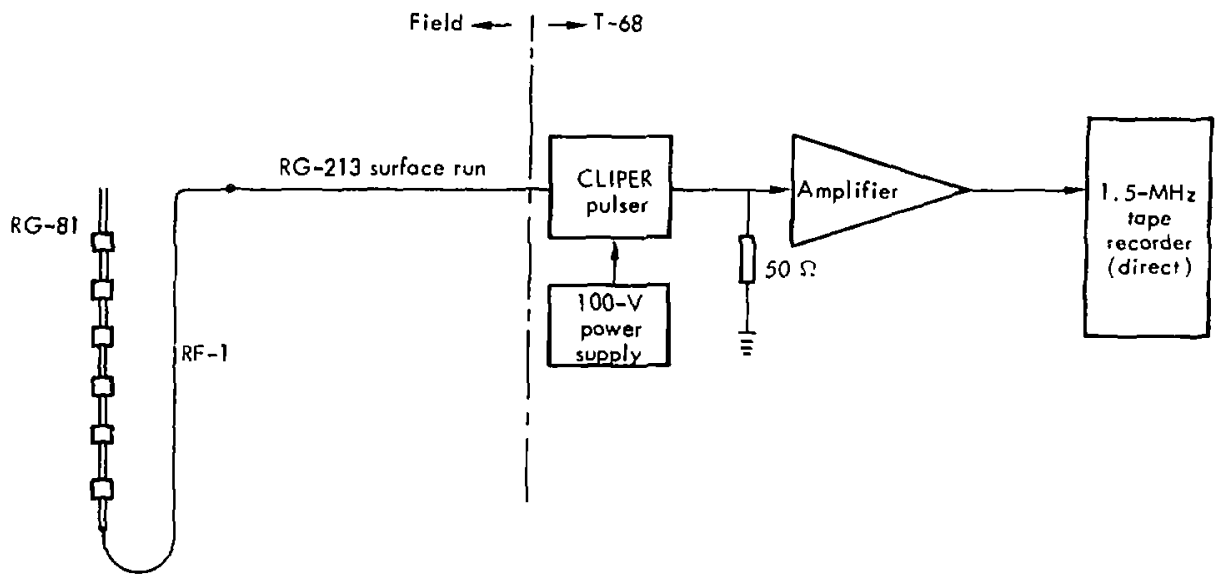

Fig. 18, Block diagram of a CLIPER system. 


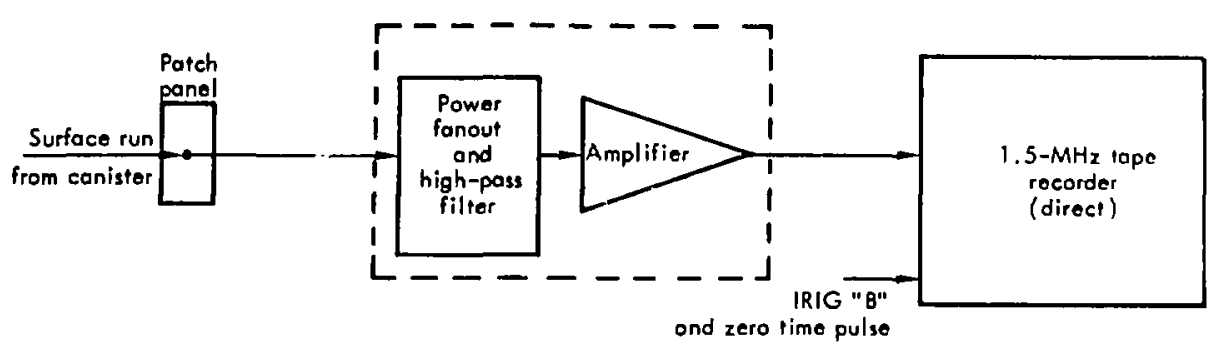

Fig. 19. Block diagram of a channel for recording data irom downhole canister.

The pulses were delivered to Traller 68 via RG-213 surface-run cable.

\section{TRAILER-68 INSTRUMENTATION}

\section{Downhole Canister Signals}

All connections to the spall canisters entered Trailer 68 and terminated at a coaxial patch panel. From there, cables were run to modified Power Fanout and High Pass Filter-Amplifier units, LEA 69-1061, (see Fig. 19). The amplifiers in these units, which were normally high passed at $300 \mathrm{kHz}$, had to be modified to accept the $125-\mathrm{kHz}$ yelocity gage gignal. This was done by removing the front-end filter and changing the size of the coupling capacitor. The amplufier gains were set so that the multiplexed signal to the tape recorder was approximately $3 \mathrm{~V}$, peak to peak. The voltage delivered at the canister was $28 \mathrm{~V}$, resulting in typical currents of $200 \mathrm{~mA}$ per canister. Voltage, current, and canister signals were monitored daily.

Individual VCO frequencies were monitored by routing the multiplexed signals through 3 bandpass filters in parallel, each tuned to the nominal center frequencies of $125 \mathrm{kHz}, 300 \mathrm{kHz}$, and $1200 \mathrm{kHz}$. These carriers were then displayed on an oscilloscope and frequency counter.
The multiplexed signalo from the Power Fanout and High Pass Filter-Amplifier units were delivered to wide-band tape recorders, one canister multiplexed bignal per track.

Two wide-band direct-record tape units were used - one Ampex Model FR-1800 and one Ampex Model FR-1900. Track 14 of each recorder was reserved for a mixed time code (IRIG B) and zero time signal. Remote start, stop, and monitor light indication from Trailer 95 (CP) was used.

\section{CLIPER Signals}

The CLIPER pulser signal output was delivered to a $50-\Omega$ terminated, wide band amplifier and then to the tape recorder. An external $100-\mathrm{V}$ power supply was used for the output aval anche transistor collector supply. Before and during installation of the CLIPER system, the lengths of the 3 individual cables ( $R G-213$ surface run, RF-1 downhole cable, and RG-81 cliper cable) for each hole were monitored by counting the pulse repetition frequency with a period counter. Daily measurements, before and after the shot, checked system stability and changes (if any) in cable lengths. 


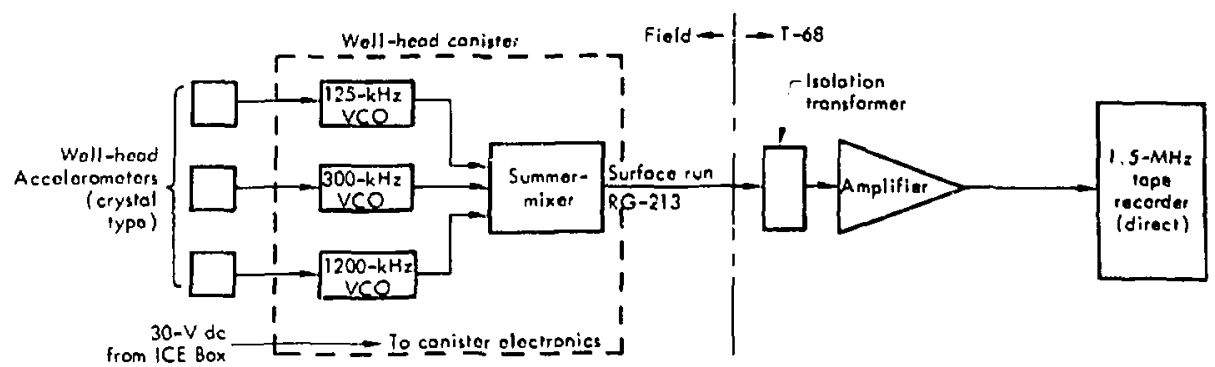

Fig. 20. Block diagram of the crystal accelercmeter system that was placed on the wellhead.

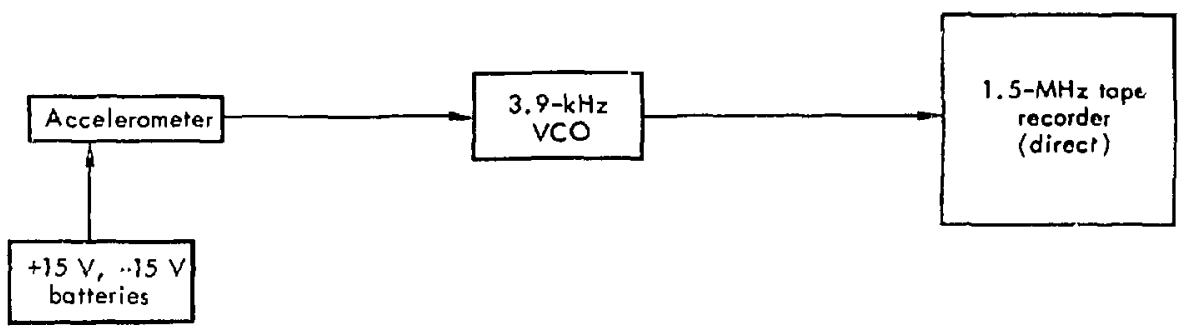

Fig. 21. Block diagram of the accelerometer used to measure the response of Trailer 68 to ground shock.

\section{ADDITIONAL INSTRUMENTATION}

Wellhead Accelerometers

Three crystal accelerometers (Fig. 20) were mounted on the wellhead and were used to deviate 3 VCOs, center tuned to the same spall frequencies. The VCO outputs were summed and delivered to Trailer 68 via RG-213 surface cables. An isolation $t r a n s$ former vas used in the trailer to prevent possible electromagnatic noise from crosstalking into the spall instrumentation system. The canister was placed above the wellhead on a wouden frame and was powered by a $28-V$ source from the ICE Box.
Trailer Response Accelerometer

A Kistler $305 \mathrm{~A}$ servo accelerometer was mounted on one of the instrumentation racks in Trailer 68 to measure the trailer response to ground shock. This signal was to be compared with the surface accelerometer signal just outside the trailer to give us data on the effectiveness of the trailer shock mitigation system. The accelerometer was battery pow rred and deviated a 3.9-kHz VCO, LEA 70-1162. The VCO signal was delivered to the tape recorder (see Fig. 21 ).

\section{Water Well Pressure Measurements}

We used Trailer 68 to record pressures from 3 different wells in and near the 


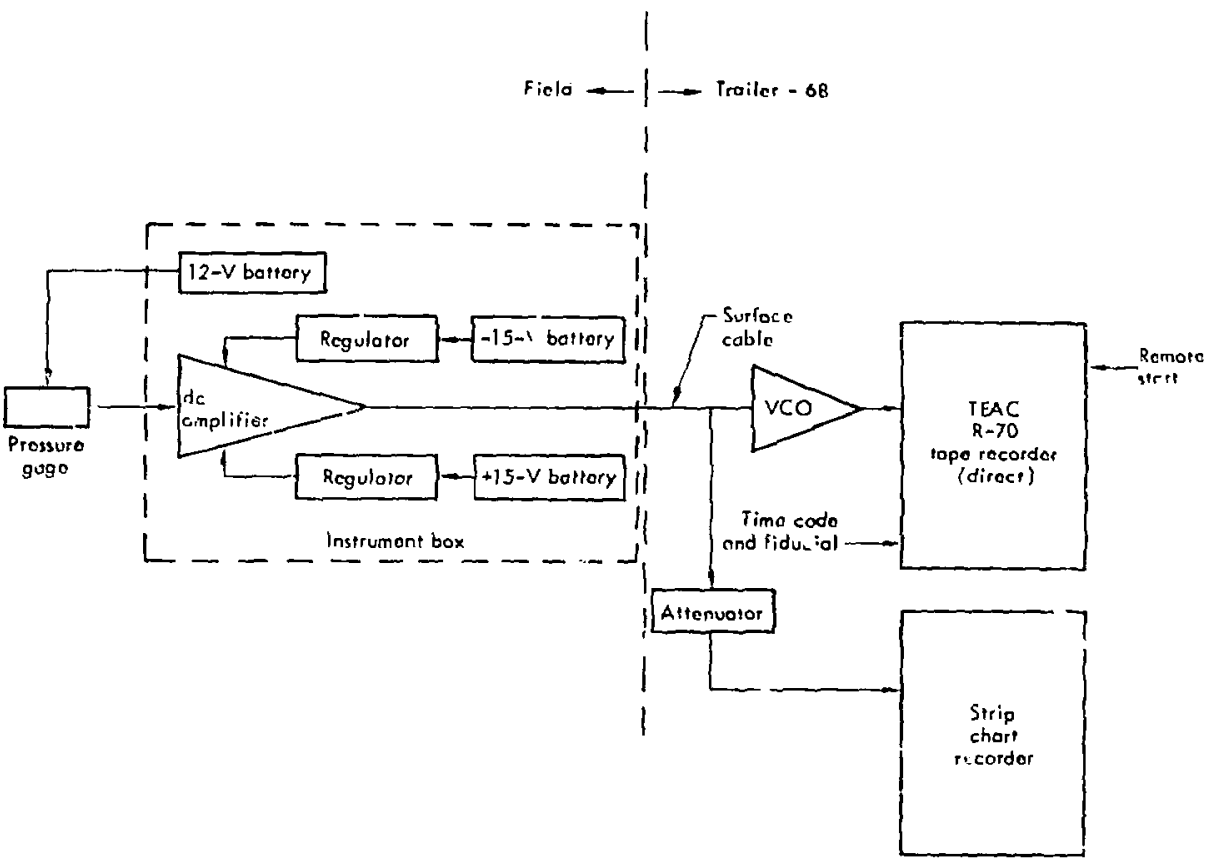

Fig. 22. Block diagram of a typical system used to record water-well pressures for the United States Geological Survey.

emplacement well for the United States Geological Survey. Figure 22 shows the instrumentation used in recording these measurements. The Uslis supplied the strain gage pressure gages, strip chart recorders, and all equipment in the instrument box. LLI supplied the surface cable, VCOS, LEA 70-1162, and tape recorder. The object of this experiment $w$ as to measure dynamic water pressure at shot time and the quasistatic decay for several hours after the shot. This was part of a continuing study by the USGS, who have made these measurements on several nuclear events.

\section{DISCUSSION AND RESULTS}

\section{Downhole Me asurernents}

The overall results from the Rio Blanco spall measurements were very good. Data was received on every one of the 59 individual carrier and CLIPER signals.

Figure 23 is a block diagram of the preliminary data playback system. Surface spall was clearly detected at all surface stations except the one at $7.3 \mathrm{~km}$. In the emplacement-well area, ground spall was detected down to about $107 \mathrm{~m}$ below ground surface. This spall zone depth diminished to less than $91 \mathrm{~m}$ at a $800 \mathrm{~m}$ 


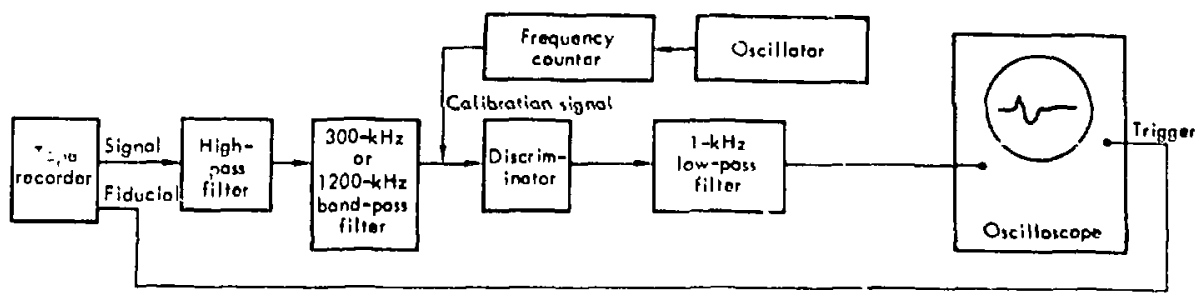

(o) Accoleromotor playback

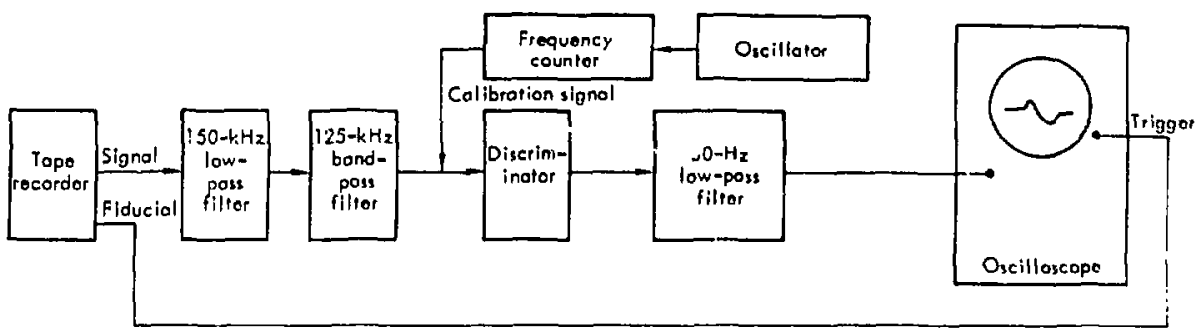

(b) Volocity gago ploybock

Fig. 23. The data playback system.

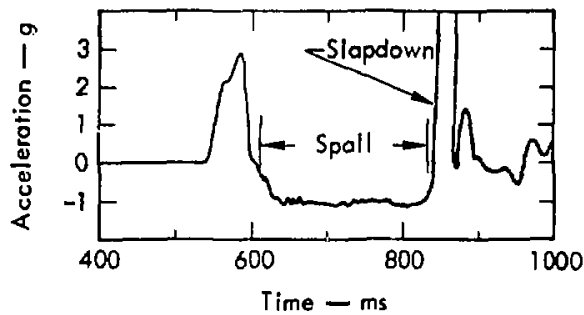

Fig. 24. Accelerorneter trace from surface station 3 . The data shows clear evidence of spall.

radius and to less than $61 \mathrm{~m}$ at $2.4 \mathrm{~km}$ from the wellhead. Thus, the earth spall zone took the shape of a large, shallow bowl with a radius of 3.6 to $7.3 \mathrm{~km}$ and a maximum depth at the "center" of the bowl of about $107 \mathrm{~m}$.

None of the five CLIPER cables broke during the shot. This was verified from preshot and postshot measurements.

This indicated that ground layer separa- tion did not exceed 7 to $10 \mathrm{~cm}$ anywhere in the spali zone.

Figures 24-26 show the differences in the data between areas where spall did
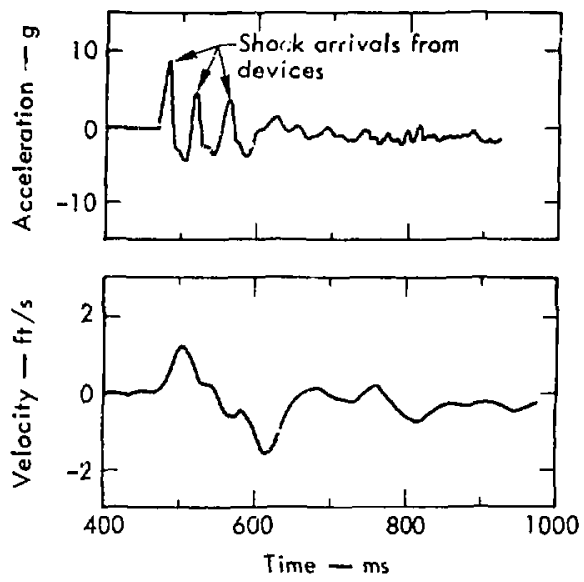

Fig. 25. Signals from canister 02-600. 


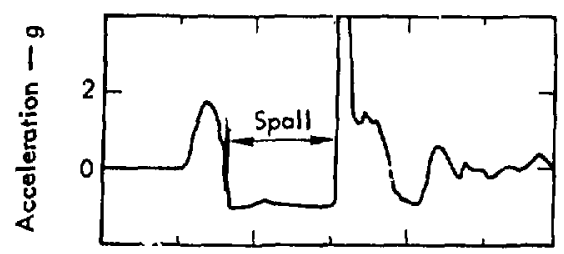

(a)

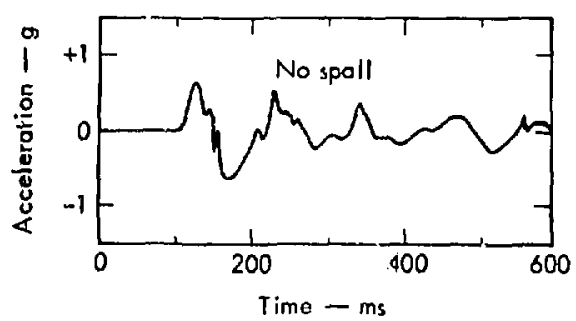

(b)

Fig. 26. Signals from the $7.3-\mathrm{km}$ surface station.

and did not occur. The Rio $\mathrm{Bl}$ anco spall data has since been digitized and computer analyzed and put in its final for $\mathrm{r}_{i}$."

Wellhead Accelerometers

The three crystal accelerometers which were mounted on the wellhead showed higher frequency acceleration components than did the spall accelerometers. All three units showed a $r$ ather large spike (up to $30 \mathrm{~g}^{\prime} \mathrm{s}$ ) at $\mathrm{T}+560 \mathrm{~ms}$

\section{Trailer Response Accelerometer}

The trailer response to the ground shock was monitored and revealed a longer duration $-1 \mathrm{~g}$ free flight than did any of the surface canisters. An initial peak acceleration of $2 \mathrm{~g}$ at about $670 \mathrm{~ms}$

"C. Sisemore and J. Toman, Project Rio Blanco Spall Measurements Data Report, Lawrence Livermore Laboratory, Riot. UCRL-51484 (1974). was followed by about $330 \mathrm{~ms}$ of $-1 \mathrm{~g}$ free flight. This $-1 \mathrm{~g}$ free flight time was at least $50 \%$ longer than any other station response. The slapdown spike was in excess of $3 \mathrm{~g}$. A comparison of this record to the accelerometer signal just outside the trailer siowed a shock reduction of at least a fictor of two.

Although the traller slapdown caused no introduction of noise on the tape recorded data, it was the cause of another problem which will be mentloned later.

\section{USGS Instrumentation}

The three water well pressures vere recirded roth on tape and strip chart. Dynamic pressure spike s of up to several hundred psi were recorded as the shock wave passed through the wells. Quasistatic long term data was recorded on the strip charts and showed a slow decrease in pressure asymptotically approaching the preshot level.

\section{PROBLEM AREAS}

Several problems occurred during the initlal system design and procurement and preshot and postshot fielding. It is worthwhile mentioning some of the more critical ones and the solutions to them.

\section{Crosstalk Between VCCE}

We initially decided to use vCO frequencies of $125 \mathrm{kHz}, 600 \mathrm{kHz}$, and $1200 \mathrm{kHz}$ for the dowizhole canister signals. Consequently, the VCOs were all tuned accordingly. During the course of our preshot shock testing of the cunisters on the Hyge machine, we discovered a serious crosstalk condition existing between the $600-$ and $1200-\mathrm{kHz}$ signals. 
A spectral analysis of those two carriers showed the second harmonic of the $600 \mathrm{kHz}$ carrier booming "loud and clear" into the $1200-\mathrm{kHz}$ signal. The decision $w$ as made to retune all the $600-\mathrm{kHz}$ VCCs to $300 \mathrm{kHz}$ to alleviate this problem. When further shock testing showed no crosstalk conditions, the canisters were sealed and shipped to Colorado.

\section{Canister Fallures}

The emplacement of the spall instrumentatioil took place during $J$ aniady and February. All systems were operating st the time we left. A three day return trip $w$ as made in late March to check on the status of all systems. It $w$ as found that one cinister, $U \dot{q}-060$, had falled completely. and one other, 02-450, showed intermittent operation.

Canister 04-060 was drawing about 10 times the nominal current and no carriers were present. This suggested possibly that water had gotten into the downhole connector and created a partial short. It was decided to replace this canister with a spare. A new hole was drilled and the spare canister emplaced with no further problems.

Canister 02-450 was intermit: ently drawing no current and twice nominal current. Since the canister was at a depth of $450 \mathrm{ft}$, replacement was not feasible. It was decided to isolate that canister from the rest of our instrumentation system by powering it from a separate $30-\mathrm{V}$ source and routing the carriers to a separate amplifier. The carriers were about $10 \%$ off of their nominal outer frequency and low in amplitude. Good quality data (in terms of the signal- to-noise ratio and waveshape) was recelved from that canister at shot time. However, amplitudes may be questionable because of the erratic performance and shift of the center frequencies.

Each canister had a thermistor bead which was used to monitor temperature. This was required in order to properly adjust velocity gage sensitivities at shot time. Many of the thermistors failed between January and May. The mode of fallure was the same in all cases-a drastic lowering of thermistor resistance. Presumably, the bead became shunted by water contamination in the $c$ a: ister connector. However, enough data was recorded before fallure (temperatures were monitored several times a week) so that we were confident that the temperatures were stablized and did not chan ;e at shot time.

\section{Fire in Trailer 68}

On D- 1 day, just a few hours before the final dry run, a fire broke out in the traller. One of the oscilloscope blower motors overheated and ignited the ollimpregnated air-flow filter. Flames then melted the rubber insulition off of some of the cables behind the rack. The fire was put out quickly with a dry chemical extinguisher. The final dry run was delayed several hours while we replaced cables and cleaned open relay contacts (used to start the tape recorders) that had become contaminated with the residue from the extinguisher. A good final dry run was conducted later that day afte: several other tests were made to insure that the relays would consistently start the tape recorders 


\section{Power Drop Out at Shot Time}

The most heart-sinking event of the entire experiment occurred on reentry into Traller 63, some two to three hours after shot time, when it was discovered that there was no power on the instrumentation equ:pment. Further observations show $\vec{A}^{\mathrm{a}}$ the instrumentation main power line contactor to be open. After restoring power by resetting the contactor, it became evident what had happened. The ground ghock at the trailer had caused a small control relay to open up, which in turn opened the large contactor. The small control relay is normally activated by an electrical timer which $c$ an be used to automatically shut down power at some preselected tirne after zero time. This feature was at one time uscd for shots at the NTS.

Further investigation revealed that the small control relay spring tension was so weak that a small rap of the hand on the box that housed the relay was sufficient to open it, and hence the main power contactor.

Later tape playbacks showed that loss of signals caused by the power fallure occurred at $1.065 \mathrm{~s}$ after zero time. Fortunately, this was enough time to capture all parts of the data from all canisters, so that there was no loss of data.

Future use of Traller 68 on an event will require that this automatic shutdown feature be bypassed to prevent reoccurrence of this problem.

\section{Velocity Gage Sensitivities}

All velocity gage signals were much lower than predicted - by ahout a factor of 10 or so. Consequently, we were far overranged and had a poor signal-to-noise ratio on these gage signals. The noise was predominately high frequency while the data was in the range of 1 to $5 \mathrm{~Hz}$. We overcame the problem without too much effort by low-pass filtering the data at $30 \mathrm{~Hz}$.

\section{Field Coordination}

The field coordination effort involved the installation and maintenance of cables and equipment as well as the coordination of all Electronics Engineering Department activities with other groups and agencies. During the period from early January 1973 to late May 1973 three trips were made to the Rio Blanco Site in connection with spall measurement, gas sampling, ICS, USGS, diesel-generator power systems, prearming, arming, and reentry detonation activities.

\section{SPALL MEASUREMENTS PROGRAM}

Field effort on the Spall Program consisted of laying over $2150 \mathrm{~m}$ of cable and locating the instrumentation trailer (T-68) and power trailer (T-11), CER Geonuclear provided a crew of electricians to lay 18 runs of RG-213 from the instrument trailer $(T-68)$, which was located at the 800-m station, to the emplacement well and to the 2225-m station (see Fig. 2). Two multiconductor cables for commnnds 
and a fiducial cable were run between $T-68$ and the ice box location at the emplacement well.

Two runs of Sandia white wire were laid from $T-68$ to the emplacement well and the $370 \mathrm{~m}$-well north of the EW for the USGS experiment. We assisted the USGS people and provided recording space in $T-6 B$ for them.

Electrical support was provided for the gas sampling system. The gas sampling tube had to be shielded due to the radiation hazard aind protected from freezing temperatures. A thermistor controlled heat tape was taped to the ras sampling tube for heating. 'his $w$ as then insulated and buried underground for shielding. A power cable and ground wire were also buried from the wellhead to a backboard near the power box. This was to provide a common ground and power to the wellhead heate:. An additional backboard was installed at the gas sampling skid to furnish power at that location. Both backboards were tied together and could be powered irom either commercial or diesel sources.

\section{INTEGRATED CONTROL SYSTEM}

The ICE Box, power box, and RT box were spotted at the emplacement well location. As shown in Fig. 2, the ICE Box was lccated about $60 \mathrm{~m} \mathrm{NW}$ of the emplacement well and the $R T$ box about $250 \mathrm{~m} \mathrm{NW}$ of the emplacement well on a line-of-sight path for microwave communication with the CP. The CP (Trailer 95) and power traile- werc spotted on a plate au overlooking the emplacement well at an elevation of $3300 \mathrm{n}$. Six RG-213 caules were laid between the ICE Box and the RT box. Two power cables were laid between the power box and RT box. The power cables were terminated by the CER electricians and the coaxial cable was terminated by LLL technicians, A $6-\mathrm{m}$ antenna tower was installed by $C E R$ at the RT box.

The ICE Box, power box, and the RT box were shock mounted. The microwave antennas were carefully supported to ensure the proper functioning of the ICS during the ground motion after detonation (see Fig. 6). A grounding system was tied to the Ice Box through a knife switch so it could be ungrounded if desired. The ground from the wellhead also went through a knife switch on the tackboard near the power box. All grounds were lifted during shot time.

Miscellaneous activities included the maintenance of the power-box diesels and provision of a flash bulb at the EW to provide a zero time marker on the motion picture film. All our trailers were prepared for shipment to LLL on $\mathrm{D}-2$ by Plowshare EE personnel. The surface run RG-213 cables were to be rereeled and returned to the NTS by CER personnel. The gas sampling system was left intact for postshot analysis.

\section{Acknowledgments}

The authors wish to express their gratitude to the Electronics Engineering Depart- ment personnel who participated in this project; Joseph H. W'ujek for his effort on 
the Safety and Reliability Analysis, John M. Brenkwitz for his effort on the monitor system and Donald $M$. Wythe for his effort on the design and fielding of the microwave system. We also wish to express our appreciation to John E. Campbell. William W. Dalton, Gary R. Thompson, and Nicholas L. Williams for their superb support. 